\title{
Article \\ Efficient Recovery of Rare Earth Elements (Pr(III) and Tm(III)) From Mining Residues Using a New Phosphorylated Hydrogel (Algal Biomass/PEI)
}

\author{
Chunlin He ${ }^{1}$, Khalid A.M. Salih ${ }^{1} \mathbb{D}$, Yuezhou Wei ${ }^{1,2}{ }^{\mathbb{D}}$, Hamed Mira ${ }^{3}$, Adel A.-H. Abdel-Rahman ${ }^{4}$, \\ Khalid Z. Elwakeel ${ }^{5,6}$, Mohammed F. Hamza ${ }^{1,3, * \mathbb{D}}$ and Eric Guibal ${ }^{7, * \text { (D) }}$
}

1 Guangxi Key Laboratory of Processing for Non-Ferrous Metals and Featured Materials, School of Resources, Environment and Materials, Guangxi University, Nanning 530004, China; helink@gxu.edu.cn (C.H.); Immortaltiger7@gmail.com (K.A.M.S.); yzwei@gxu.edu.cn (Y.W.)

2 School of Nuclear Science and Engineering, Shanghai Jiao Tong University, Shanghai 200240, China

3 Nuclear Materials Authority, P.O. Box, El-Maadi, Cairo 530, Egypt; hamedmira@yahoo.com

4 Faculty of Science, Menoufia University, Shebine El-Koam 00123, Egypt; adelnassar63@yahoo.com

5 Department of Chemistry, College of Science, University of Jeddah, Jeddah 23218, Saudi Arabia; kelwkeel@uj.edu.sa

6 Environmental Science Department, Faculty of Science, Port-Said University, Port Said 42526, Egypt

7 Polymers, Composites and Hybrids, Institut Mines Telecom-Mines Ales, F-30100 Ales, France

* Correspondence: m_fouda21@hotmail.com (M.F.H.); eric.guibal@mines-ales.fr (E.G.); Tel.: +2-01116681228 (M.F.H.); +33-(0)466782734 (E.G.)

Citation: He, C.; Salih, K.A.M.; Wei, Y.; Mira, H.; Abdel-Rahman, A.A.-H.; Elwakeel, K.Z.; Hamza, M.F.; Guibal, E. Efficient Recovery of Rare Earth Elements (Pr(III) and Tm(III)) From Mining Residues Using a New Phosphorylated Hydrogel (Algal Biomass/PEI). Metals 2021, 11, 294. https://doi.org/10.3390/met11020294

Academic Editor: Laura Castro

Received: 11 January 2021

Accepted: 2 February 2021

Published: 8 February 202

Publisher's Note: MDPI stays neutral with regard to jurisdictional claims in published maps and institutional affiliations.

Copyright: (c) 2021 by the authors. Licensee MDPI, Basel, Switzerland. This article is an open access article distributed under the terms and conditions of the Creative Commons Attribution (CC BY) license (https:/ / creativecommons.org/licenses/by/ $4.0 /)$.
Abstract: With the target of recovering rare earth elements (REEs) from acidic leachates, a new functionalized hydrogel was designed, based on the phosphorylation of algal/polyethyleneimine beads. The functionalization strongly increased the sorption efficiency of the raw material for $\operatorname{Pr}(\mathrm{III})$ and Tm(III). Diverse techniques were used for characterizing this new material and correlating the sorption performances and mechanisms to the physicochemical structure of the sorbent. First, the work characterized the sorption properties from synthetic solutions with the usual procedures (study of pH effect, uptake kinetics, sorption isotherms, metal desorption and sorbent recycling, and selectivity from multi-element solutions). Optimum $\mathrm{pH}$ was found close to 5; sorption isotherms

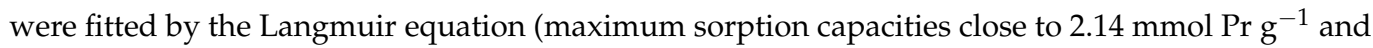
$1.57 \mathrm{mmol} \mathrm{Tm} \mathrm{g}^{-1}$ ). Fast uptake kinetics were modeled by the pseudo-second order rate equation. The sorbent was highly selective for REEs against alkali-earth and base metals. The sorbent was remarkably stable for sorption and desorption operation (using $0.2 \mathrm{M} \mathrm{HCl} / 0.5 \mathrm{M} \mathrm{CaCl}_{2}$ solutions). The sorbent was successfully applied to the leachates of Egyptian ore (pug leaching) after a series of pre-treatments (precipitation steps), sorption, and elution. The selective precipitation of REEs using oxalic acid allows for the recovery of a pure REE precipitate.

Keywords: rare earth elements; sorption isotherms; uptake kinetics; functionalization of bio-based sorbent; metal desorption; sorbent recycling; treatment of ore leachate

\section{Introduction}

Rare earth elements (REEs) are widely used in the design of high-tech devices [1]. For example, praseodymium is used for elaborating advanced alloys (aircraft industry), refractory substances, coloring materials, lighting equipment, and fiber optical cables [2]. Thulium is an expensive REE that is used for designing x-ray emitters, medical and astronautic lasers [3], high-temperature superconductors, ferrite alloys, and ceramic magnetic materials in microwave equipment. In addition to their relatively expensive costs, the geopolitical distribution of resources and exploitation facilities of these metals are making these elements strategic targets, so there is great attention toward developing recovery processes from low-grade minerals and/or from industrial wastes [4]. Their rarefaction, 
cost, and weak recycling rate (less than $10 \%$ for both Tm and Pr, [5]) justify the importance of designing new processes for their recovery from low-grade resources [6].

Their recovery proceeds as sub-products from the processing of other metals from diverse resources: red mud valorization, phosphoric acid synthesis from phosphate ores [7], and ore leachates. The usual hydrometallurgical processes such as solvent extraction [8] and sorption on resins [9-11] can be applied for the treatment of high or low concentration effluents, respectively [12]. The complexity of the leachates (due to the presence of many transition metals) requires developing processes efficient for the separation of REEs from base metals [13]. Furthermore, the physicochemical properties of the members of the REE family are so close that their separation is usually very complex, requiring long chromatographic columns with many theoretical plateaus. These separation issues represent important global challenges for designing competitive processes for the selective recovery of REEs.

There has been an impressive effort, demonstrated by the numerous literature published over the last decade, in developing new sorbents bearing the same reactive groups as those active in the extractants used in solvent extraction [14-18]. Sorbents have been designed by the functionalization of clays for the recovery of REEs [19] and the preparation of composites based on silica [20-23] or carbon-based supports [21,24,25]. Synthetic resins have been functionalized with phosphorus groups [26-31], taking advantage of the affinity of phosphonic-based reactive groups for REEs.

Biosorption processes have already been reported for the recovery of REEs including algal biomass [32,33] and alginate (a polysaccharide bearing guluronic and mannuronic acid groups) [34-39]. Alginate is frequently used for metal sorption making profit of the reactivity of carboxylate groups [40,41], but also as a constituent of composite sorbents [42]. Recently, the combination of (a) specific interactions of alginate (partially extracted from algal biomass) with poly(ethyleneimine) (PEI), the ionotropic gelation of alginate with calcium chloride, and the crosslinking of amine groups (of PEI) with glutaraldehyde (GA) was used for synthesizing composite hydrogel beads (algal-polyethyleneimine beads, APEI) [43]. These supports have been functionalized by grafting amidoxime groups for Sr(II) sorption [44], sulfonic groups for the recovery of REEs [45], and by quaternization for Sc(III) removal [46]. The current work describes the synthesis of phosphorylated APEI beads (P2-APEI). The support (i.e., APEI) is activated with epichlorohydrin (APEI$\mathrm{Cl}$ ) (which is subject to a partial polymerization under selected experimental conditions) before being reacted with triethyl phosphine. After physicochemical characterization (using various analytical tools), the phosphonated-functionalized sorbent (i.e., P2-APEI) is extensively investigated for the sorption of $\operatorname{Pr}(\mathrm{III})$ (which is part of light REE, LREEs) and Tm(III) (representing heavy REEs, HREEs). After $\mathrm{pH}$ optimization, the uptake kinetics and sorption isotherms are investigated using conventional models for fitting experimental profiles. The selectivity properties are investigated against transition metals at different $\mathrm{pH}$ values to evaluate the possibility to separate base metals from REEs, but also to discuss the possibility of separating the rare earths (LREEs vs. HREEs). The elution of REEs is investigated and applied for five cycles of sorption and desorption for evaluating the potential of the sorbent to be re-used. In the last section of this work, the sorbent is tested for the recovery and separation of REEs from the acidic leachates of waste residue of Egyptian ore. This section includes the study of the pre-treatment of leachates, the sorption process, the elution of the loaded sorbent, and the final precipitation of REEs as oxalate salt.

\section{Materials and Methods}

\subsection{Materials}

Brown algae (Laminaria digitata) was provided by Setalg (Pleubian, France). After washing, drying, and grinding, the biomass was sieved to recover the fraction below $250 \mu \mathrm{m}$. Alginate (Manugel GMB) was supplied by DuPont (Landerneau, France; now JRS Rettenmaier). Other reagents such as sodium carbonate $\mathrm{Na}_{2} \mathrm{CO}_{3}(99.8 \%)$ and calcium chloride $(96 \%)$ were purchased from Chem-Lab NV (Zedelgem, Belgium). Branched 
polyethyleneimine (bPEI, 50\% $(w / w)$ in water) and glutaraldehyde (GA, 50\% $(w / w)$ in water) were purchased from Sigma-Aldrich (Taufkirchen, Germany).

Epichlorohydrin (98\%) and triethyl phosphite (98\%) were purchased from Shanghai Makclin Biochemical Co. Ltd. (Shanghai, China). Zinc oxide (98\%) (for selectivity exp.) was supplied by Aladdin Industrial Corporation (Shanghai, China). Aluminum sulfate octadecahydrate (99\%) (used in selectivity experiments), sodium hydroxide (96\%), and absolute ethanol (99.7\%) were supplied by Guangdong Guanghua Sci-Tech (Guangzhou, China). Acetone (95.5\%) and sulfuric acid $(98 \%)$ were purchased from Chron Chemicals (Sichuan Province, China). Praseodymium sulfate (99.99\%) and thulium sulfate (99.99\%) were supplied by National Engineering Research Center of Rare Earth Metallurgy and Functional Materials Co. Ltd. (Baotou city, Inner Mongolia, China). Silicon with conc. (1000 ppm) as a source of $\mathrm{Si}$, which was supplied by Guobiao Inspection and Certification Co. Ltd. (Huairou District, Beijing, China). The other reagents were Prolabo products and were used as received.

\subsection{Synthesis of Sorbents}

\subsubsection{Synthesis of Algal/Poly(ethyleneimine) (PEI) Beads (APEI)}

The algal/PEI beads were prepared according to a method previously described by Wang et al. [43]. Briefly, $18.75 \mathrm{~g}$ of dry algal biomass was dispersed into $750 \mathrm{~mL}$ of $\mathrm{Na}_{2} \mathrm{CO}_{3}$ solution $(1 \%, w / w)$ under agitation and heating $\left(50^{\circ} \mathrm{C}\right)$ for $24 \mathrm{~h}$. After cooling, a volume (i.e., $250 \mathrm{~mL}$ ) of alginate solution $(4 \%, w / w)$ was added to biomass suspension. A volume of $5 \mathrm{~mL}$ of bPEI solution $(50 \%, w / w)$ was added to $500 \mathrm{~mL}$ of the mixture under agitation. The algal biomass/alginate/ bPEI suspension was distributed into a 1-L volume of a solution containing both $\mathrm{CaCl}_{2}(1 \%, w / w)$ and GA $(5 \mathrm{~mL}, 50 \%, w / w)$. The beads (APEI) were maintained under agitation overnight in the crosslinking solution before being filtrated and freeze-dried. The size of the APEI beads was $2.9 \pm 0.2 \mathrm{~mm}$. The successive steps in the functionalization of APEI beads are reported in Scheme 1 .

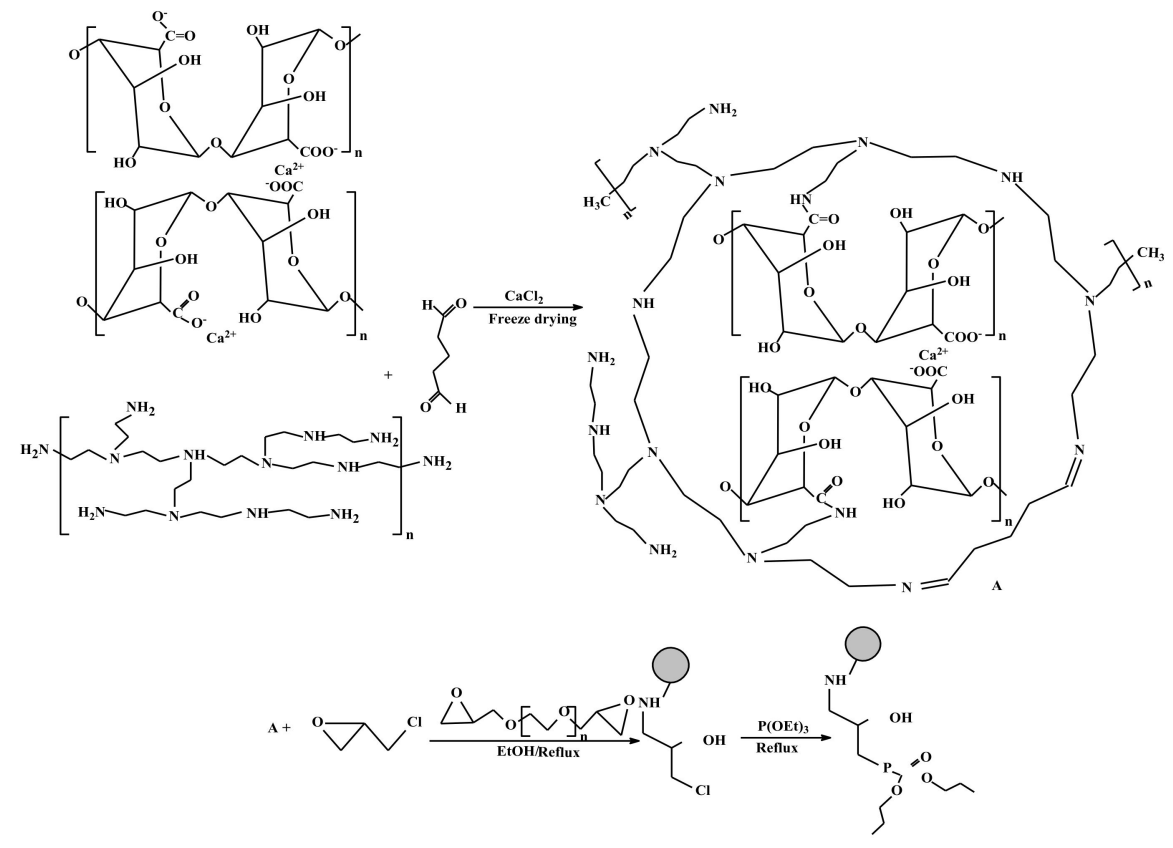

Scheme 1. Synthesis pathway for the synthesis of P2-APEI sorbent (A: poly(ethyleneimine) (APEI) synthesis).

\subsubsection{Synthesis of Activated APEI Beads (Methylene Chloride Grafted Spacer Arms)}

Two grams of raw beads were immersed in $90 \mathrm{~mL}$ of ethanol:water (50:50: $v / v$ ) before adding $18 \mathrm{~mL}$ of epichlorohydrin drop-wise with gentle stirring, then the mixture was refluxed at $80^{\circ} \mathrm{C}$ for $3 \mathrm{~h}$. The reaction mixture was filtered off, stirred with ethanol for 
$24 \mathrm{~h}$, then filtered again and dried in vacuum to give beads with active methylene chloride (spacer arm).

\subsubsection{Phosphorylation of APEI Activated Beads (P2-APEI)}

The produced active methylene chloride beads from the previous step were heated at $120-130{ }^{\circ} \mathrm{C}$ with $40 \mathrm{~mL}$ of triethyl phosphite for $24 \mathrm{~h}$ to produce phosphoryl group derivatives. The functionalized beads were filtered off and washed several times with ethanol and vacuum dried overnight. The size of the APEI beads was $2.8 \pm 0.1 \mathrm{~mm}$. Scheme 2 shows the functional groups present at the surface of the sorbent.
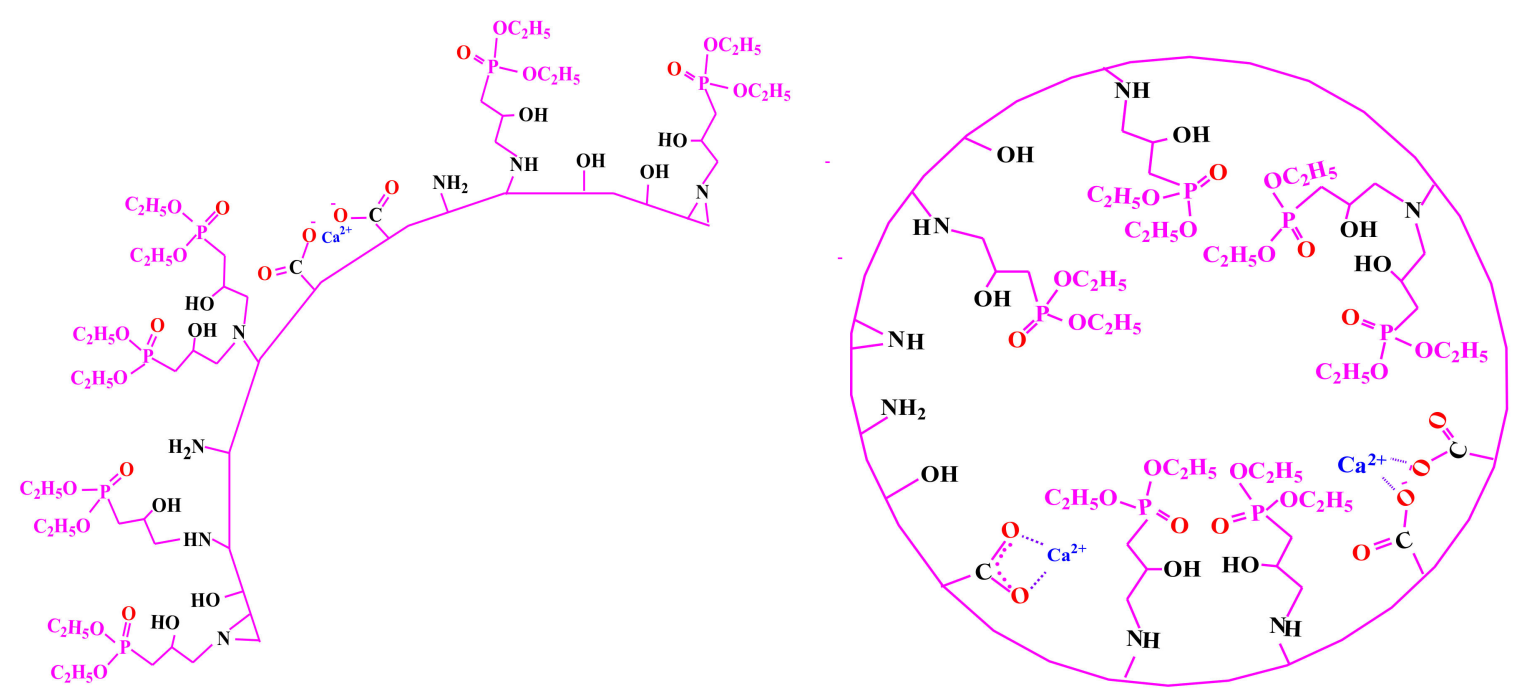

Scheme 2. Schematization of sorbent surface-functional groups.

\subsection{Characterization of Materials}

The morphology observation and the semi-quantitative surface analyses were obtained on a Phenom ProX scanning electron microscope (SEM, Thermo Fischer Scientific, Inc., Waltham, MA, USA) coupled with, energy dispersive X-ray analysis (EDX) facilities. The textural properties of the sorbents were qualified using the Barrett, Joyner and Halenda (BJH) method and a Micromeritics TrisStar II (Norcross, GA, USA). The pre-treatment of the samples consisted of their degassing at $100{ }^{\circ} \mathrm{C}$ for $12 \mathrm{~h}$. A Netzsch STA 449 F3 Jupiter thermogravimeter was used for Thermal gravimetric analysis (TGA) analysis, with a temperature ramp of $10^{\circ} \mathrm{C} / \mathrm{min}$ (under oxygen or air atmosphere) (NETZSCH-Gerätebau $\mathrm{GmbH}$, Selb, Germany). The elemental composition of the sorbents was obtained on a Vario EL cube element analyzer (Elementar Analysensysteme GmbH, Langenselbold, Germany). Fourier transform infrared spectra were collected on $\mathrm{KBr}$ discs by incorporation of dried ground samples with an IRTracer-100 (Shimadzu, Tokyo, Japan). X-ray photoelectron Spectroscopy (PS) spectra were acquired using an ESCALAB 250XI+ instrument (Thermo Fischer Scientific, Inc., Waltham, MA, USA). The $\mathrm{pH}$-drift method was used to approach the $\mathrm{pH}_{\mathrm{PZC}}$ of the materials [47]. A series of flasks containing $100 \mathrm{mg}$ of material and $50 \mathrm{~mL}$ of $0.1 \mathrm{M} \mathrm{NaCl}$ solutions with an initial $\mathrm{pH}\left(\mathrm{pH}_{0}\right)$ varying between 1 and 11 were stirred for $48 \mathrm{~h}$. The equilibrium $\mathrm{pH}\left(\mathrm{pH}_{\mathrm{eq}}\right)$ was measured using a Mettler Toledo $\mathrm{pH}$-meter (Mettler, Colombus, $\mathrm{OH}, \mathrm{USA}$ ). The $\mathrm{pH}_{\mathrm{PZC}}$ was deduced from the titration curve considering $\mathrm{pH}_{\mathrm{PZC}}$ as the $\mathrm{pH}$ verifying $\mathrm{pH}_{\mathrm{eq}}=\mathrm{pH}_{0}$.

\subsection{Sorption Tests}

Sorption tests were performed with the batch method. A fixed amount of sorbent $(\mathrm{m}, \mathrm{g})$ was mixed with a fixed volume $(\mathrm{V}, \mathrm{L})$ of solution at a specific concentration $\left(\mathrm{C}_{0}, \mathrm{mmol} \mathrm{L}^{-1}\right)$ and $\mathrm{pH}$ (variable for $\mathrm{pH}$ study, or optimized $\mathrm{pH}$ value, see below). The agitation was maintained at $170 \mathrm{rpm}$ while the standard room temperature was $\mathrm{T}: 21 \pm 1{ }^{\circ} \mathrm{C}$ 
(using a reciprocal shaker, Eyela NTS-4000C, Rikakikai Co. Ltd., Bunkyo City, Tokyo, Japan). After equilibrium (or fixed sampling times), the sample was collected and filtered through a filter membrane before analyzing metal content $\left(\mathrm{C}_{\mathrm{eq}}, \mathrm{mmol} \mathrm{L}^{-1}\right)$ by ICP-AES (inductively coupled plasma atomic emission spectrometer, ICPS-7510 Shimadzu, Tokyo, Japan). The sorption capacity ( $\mathrm{q}_{\mathrm{eq}}, \mathrm{mmol} \mathrm{g}^{-1}$ ) was deduced from concentration variation by the mass balance equation $\mathrm{q}_{\mathrm{eq}}=\left(\mathrm{C}_{0}-\mathrm{C}_{\mathrm{eq}}\right) \times \mathrm{V} / \mathrm{m}$. Similar procedures were used for investigating the sorption of REEs from multi-metal solutions (equimolar concentration: $1 \mathrm{mmol} \mathrm{L}^{-1}$ ).

The tests for metal desorption were also performed in a batch reactor. The samples of sorbents loaded with metal ions were collected from uptake kinetic experiments. The eluent was an acidic calcium chloride solution (i.e., $0.2 \mathrm{M} \mathrm{HCl} / 0.5 \mathrm{M} \mathrm{CaCl}_{2}$ ). The sorbent dosage (SD, $\mathrm{g} \mathrm{L}^{-1}$ ) was set at $0.8 \mathrm{~g} \mathrm{~L}^{-1}$. In the investigation of sorbent recycling, a rinse was systematically performed between each step. The comparison of the amounts of metal sorbed and released was used for calculating the sorption capacity and the desorption efficiency.

The precise experimental conditions are systematically reported in the caption of the figures (see below).

The uptake kinetics and sorption isotherms were fitted by conventional equations summarized in Table S1a (pseudo-first order rate equation, PFORE; pseudo-second order rate equation, PSORE; resistance to intraparticle diffusion, RIDE) and Table S1b (Langmuir, Freundlich, and Sips equations) (see Supplementary Materials). The quality of curve fitting was evaluated using the determination coefficient (i.e., $R^{2}$ ) and the Akaike information criterion (AIC) [48].

\subsection{Treatment of Ore Residues}

The solid waste that was tested for the application of P2-APEI was collected from the tailing ponds of the Abu Thora mining site (Southwestern Sinai, Egypt). The local ores were initially subjected to acid leaching; these are mainly constituted of gibbsite-bearing shales. The residue collected on-site was exploited by pug leaching for extracting supplementary valuable metals. The curing temperature was set to $120^{\circ} \mathrm{C}$.

The ore and waste residue were first digested using different acids (hydrofluoric, hydrochloric, and nitric acids). The leaching residue was removed by filtration, while the filtrate was adjusted to a final volume of $100 \mathrm{~mL}$ in a volumetric flask. The characterization of the leachate followed different methods. Aluminum, $\mathrm{Ca}, \mathrm{Fe}$, and $\mathrm{Mg}$ were analyzed by atomic absorption spectrometry (Unicam AAS-969 Vitech International BV, Geleen, The Netherlands); carbonate and phosphate analysis were processed by the Shapiro method [49]. Silica content was obtained by the molybdenum blue method and total REE concentration was evaluated by the Arsenazo III method (using Shimadzu UV-160 spectrophotometer, Shimadzu, Kyoto, Japan) [50]. Uranium was quantified by oxidimetric titration against ammonium metavanadate [51].

The complexity of the leachate and the presence of high concentrations of iron and aluminum required a pre-treatment of the solutions at $\mathrm{pH} 4$ and 5 successively using $3 \mathrm{M}$ $\mathrm{NaOH}$ solutions.

The sorption test was performed in batch with a sorbent dosage of $1 \mathrm{~g} \mathrm{~L}^{-1}$ and a contact time of $2 \mathrm{~h}$. The pre-treated leachates were adjusted at different $\mathrm{pH}$ values to evaluate the optimum $\mathrm{pH}$ for the separation of REEs from base metals (i.e., $\mathrm{pH}$ : 1.38-3.91). After sorption, the sorbent was rinsed and dispersed in the eluent (i.e., $0.2 \mathrm{M} \mathrm{HCl} / 0.5 \mathrm{M} \mathrm{CaCl}_{2}$ ); the sorbent dosage was set to $5 \mathrm{~g} \mathrm{~L}^{-1}$.

The eluates were collected and REEs were precipitated at $\mathrm{pH} 1$ using an oxalic acid solution $(15 \%, w / w)$. The concentrations of metals in both the oxalate precipitate and the sorbent (cross-section) at the end of the process were semi-quantitatively determined using EDX facilities. 


\section{Results and Discussion}

3.1. Characterization of Materials

3.1.1. Scanning Electron Microscopy (SEM) and SEM-EDX Characterizations

Table S2 shows the SEM pictures of the surface and cross-section for APEI, activated APEI (with epichlorohydrin, APEI-Cl), and P2-APEI. The surface was very dense for APEI and tended to be progressively more porous with the successive chemical modifications. On the other hand, The cross-sections were much more porous than the surfaces (especially for APEI and APEI-Cl); interconnected scaffolds can anticipate good mass transfer properties (after passing through the external "skin"). The chemical modifications contributed to altering the surface of the beads that became more porous at the level of thee external layers. The heterogeneities between the surface and the internal porous network were confirmed by the differences in the semi-empirical analyses for the three materials. For APEI, the nitrogen and chlorine contents were higher in the cross-section than at the surface of the bead. In the case of APEI-Cl, in contrast, the nitrogen and chloride contents were higher at the surface of the sorbent, while the Ca content increased in the inner compartment of the bead. The immobilization of the phosphorous reactive groups was confirmed by the appearance of the $\mathrm{P}$ signal (with an atomic concentration in the range of 5-6\% for both surface and cross-section). The percentages of $\mathrm{N}$ and $\mathrm{Cl}$ in P2-APEI decreased compared with the values reached with APEI and APEI-Cl. The concentration of O decreased between the surface and the inner compartment by around $6 \%$ for APEI and P2-APEI; this difference was less marked for APEI-Cl. These results show that the APEI sorbent is heterogeneous and that the functionalization of the support does not significantly change this trend.

\subsubsection{Textural Properties}

Figure S1 (see Supplementary Materials) compares the $\mathrm{S}_{\mathrm{BET}}$ surfaces of APEI and P2-APEI: the functionalization of the beads led to a $\sim 10 \%$ decrease in the specific surface area and the reduction in the porous volume (by 10-12\%) while the pore size slightly increased (by $5-12 \%$ ). This is consistent with the SEM observations: the larger pores of P2-APEI contribute to explaining the lower specific surface area.

\subsubsection{Thermogravimetric Analysis}

Figure S2 summarizes the weight losses of the two sorbents submitted to increasing temperatures (TGA analysis under $\mathrm{O}_{2}$ atmosphere). APEI and P2-APEI showed very similar TGA profiles. It is noteworthy that the water content was higher in APEI than in P2-APEI: the weight loss in the first segment (below 173 or $148{ }^{\circ} \mathrm{C}$ ), which represents water release, was more intense for APEI, about $11 \%$ vs. $~ 4 \%$ for P2-APEI. The highest weight losses were observed at $305{ }^{\circ} \mathrm{C}$ and $550{ }^{\circ} \mathrm{C}$ (identified on DrTG curves) for APEI. In the case of P2-APEI, the weight loss profiles were more smoothed and more steps could be detected: the DrTG profile identified four successive maxima at 303, 475, 630, and $724^{\circ} \mathrm{C}$. The functionalization of the support increased its stability. For APEI, weight loss above $600{ }^{\circ} \mathrm{C}$ was negligible, the thermal degradation was only stabilized at $750{ }^{\circ} \mathrm{C}$ for P2-APEI. The positive effect of the incorporation of phosphorous compounds in materials on their thermal stability has frequently been reported [52]. The two new peaks in the DrTG curve may be assigned to the presence of the spacer-arm and activated agent (the first step in the functionalization of APEI), and phosphorus-based compounds, respectively. The final residue (above $800^{\circ} \mathrm{C}$ ) represented about $9.7 \%$ for APEI and $11.6 \%$ for P2-APEI.

\subsubsection{FTIR Analysis}

Figure 1 reports the FTIR spectra of raw APEI beads, activated APEI beads, and phosphorylated beads. The main typical reactive groups were identified with their respective fingerprints. Table S3 reports the corresponding wavenumbers and the assignments of their respective vibrations while Figure S3 shows a focus of these spectra on specific wavenumber ranges. Briefly, the broad and poorly resolved band in the range $3700-3100 \mathrm{~cm}^{-1}$ represents the contributions of stretching vibrations for $-\mathrm{OH},-\mathrm{NH}$, and $-\mathrm{NH}_{2}$ bonds. 
The three spectra were roughly the same: APEI-Cl showed a broader spectrum with an increased contribution at around $3250 \mathrm{~cm}^{-1}$. The activation of APEI beads with epichlorohydrin grafting was confirmed by the strong peak at $788 \mathrm{~cm}^{-1}$ and the shift in the $\mathrm{C}-\mathrm{C}$ and $\mathrm{C}-\mathrm{O}-\mathrm{C}$, or $\mathrm{C}-\mathrm{O}$ stretching vibrations from $1095 \mathrm{~cm}^{-1}$ to $1089 \mathrm{~cm}^{-1}$. After functionalization, this peak disappeared: the phosphorylation was highly efficient and quantitative. Obviously, the phosphorylation was accompanied by the appearance of a series of peaks corresponding to $\mathrm{P}=\mathrm{O}$ (asymmetric stretching at $1251 \mathrm{~cm}^{-1}$ ), $\mathrm{P}(\mathrm{O})$ stretching (phosphate, at $1033 \mathrm{~cm}^{-1}$ ), and $\mathrm{P}-\mathrm{O}-\mathrm{C}$ stretching (at $611 \mathrm{~cm}^{-1}$ and $\left.746 \mathrm{~cm}^{-1}\right)$. In addition, a new peak appeared at $1741 \mathrm{~cm}^{-1}$ (assigned to $\mathrm{C}(=\mathrm{O}) \mathrm{O}$ ester stretching in alginate). In the original material and activated APEI-Cl, this peak was overlapped with C=N (GA interaction with amine groups PEI). After deconvolution, apparently, the peak split into two components corresponding to $\mathrm{C}=\mathrm{N}$ and $\mathrm{C}=\mathrm{O}$ from carboxylate because of the reduced contribution of specific $\mathrm{N}-\mathrm{H}$ groups (in the overlapping).

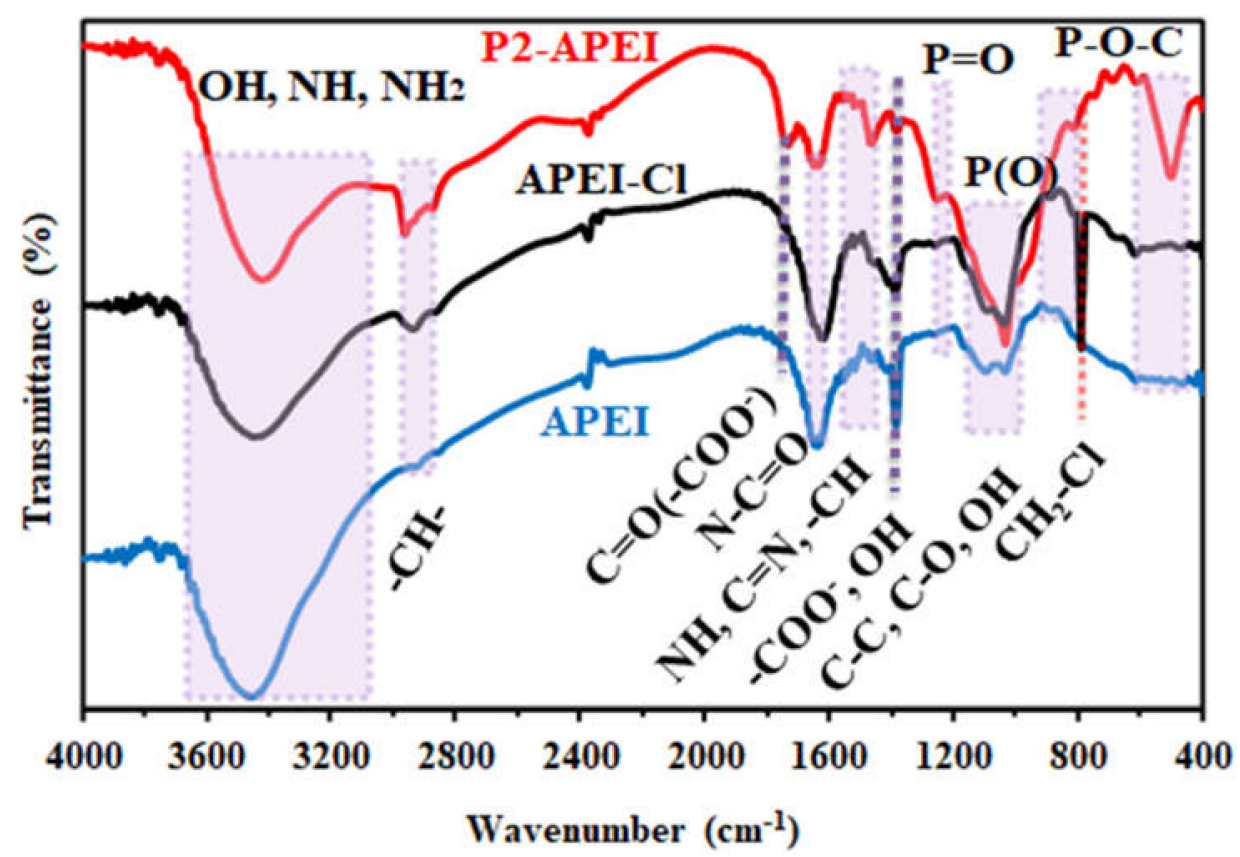

Figure 1. Fourier transform infrared (FTIR) spectra of APEI, APEI-Cl, and P2-APEI materials.

After metal sorption, the FTIR spectra were changed (Figure 2, Figure S4, and Table S4). The relative intensity of the band at $1741 \mathrm{~cm}^{-1}$ was reduced. The peak at $1384 \mathrm{~cm}^{-1}$ was completed by a shoulder at $1408-1404 \mathrm{~cm}^{-1}$, which can be assigned to carboxylate salt. This is confirmation that metal ions, at least partially, interact with carboxylate by ion-exchange with $\mathrm{Ca}$ (II). A new band appeared at $617 \mathrm{~cm}^{-1}$, which can be attributed to the sulfate anion. This means that the sorption of REEs involves the binding of a metal sulfate complex. The new peak at $1103-1111 \mathrm{~cm}^{-1}$ may be associated with the interaction of metal ions with $\mathrm{P}(\mathrm{O})$ (stretching vibration of phosphate) and/or the stretching of $\mathrm{C}-\mathrm{N}$. These results confirm that phosphate and amine groups contribute to metal binding. The contribution of amine is also correlated to the widening of the band at $3700-3100 \mathrm{~cm}^{-1}$.

It is noteworthy that the desorption of the metals (considered in relevant figures after five cycles of re-use) allowed for reversing the appearance of these new peaks. The desorption roughly restored the FTIR spectra of metal-loaded P2-APEI to the original spectrum of the sorbent, with the remarkable exception of the peak at $498 \mathrm{~cm}^{-1}$, assigned to polysulfide (S-S stretching band attributed to fucoidan, overlapped with $\mathrm{P}-\mathrm{O}-\mathrm{C}$ band) that disappeared after sorption and desorption. The relative intensity of some peaks was not completely recovered; for example, the peak at $1741 \mathrm{~cm}^{-1}$. The peak at $1103-1011 \mathrm{~cm}^{-1}$ also remained partially after metal desorption. The procedure of sorption/desorption 
appears to be efficient for restoring the material, although some chemical modifications cannot be neglected based on the changes in the FTIR spectra.

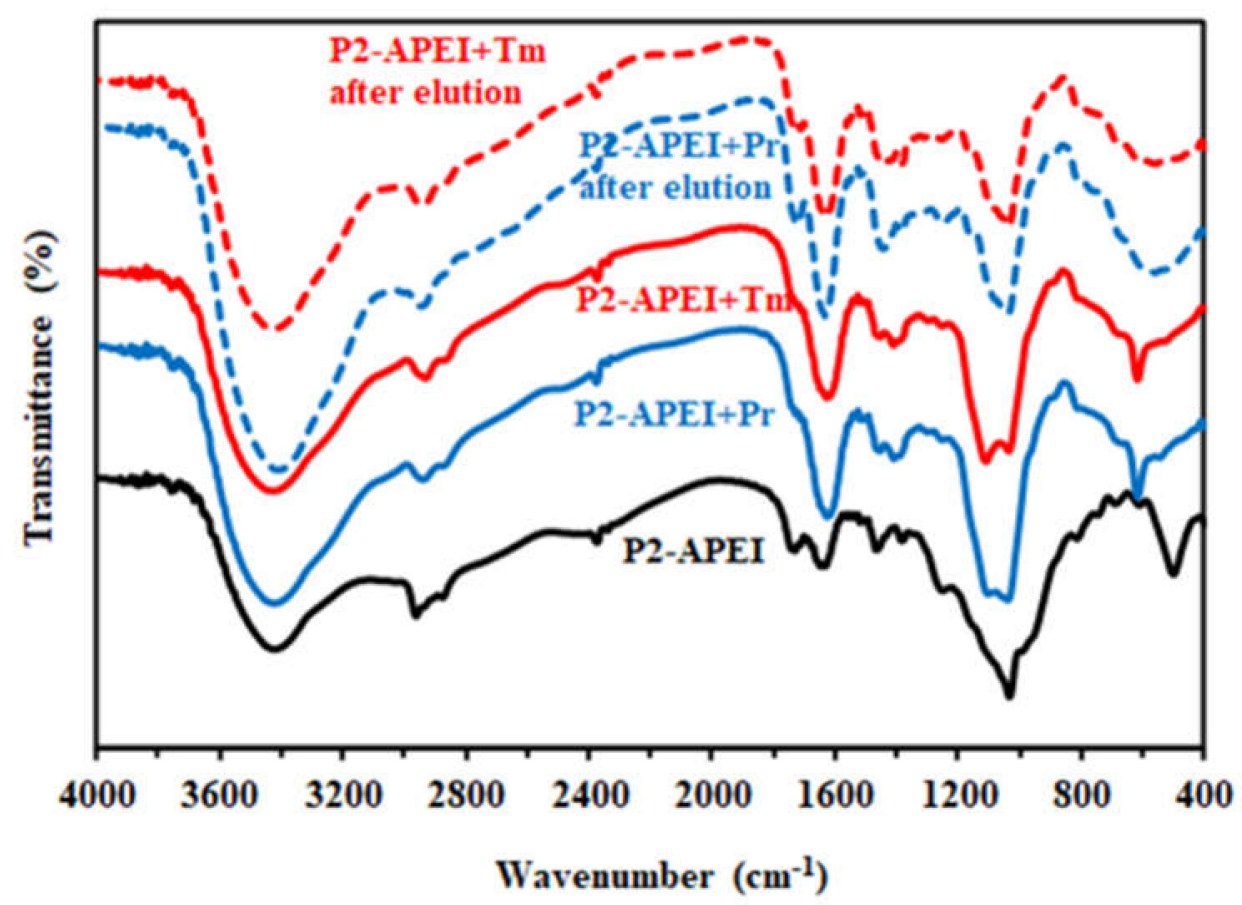

Figure 2. FTIR spectra of P2-APEI, P2-APEI sorbent loaded with $\operatorname{Pr}(\mathrm{III})$ and $\mathrm{Tm}(\mathrm{III})$, and after metal desorption.

\subsubsection{XPS Analysis}

The XPS survey scan (Figure 3) brings new evidence for the successful functionalization of APEI. The typical P $2 p$ and P 2s signals appeared at binding energies (BEs) 133 and $190 \mathrm{eV}$, respectively. The weak signal at $348 \mathrm{eV}$, which is assigned to Ca $2 p$, almost disappeared after phosphorylation as well as S 2p and S 2s signals at 167 and $228 \mathrm{eV}$, respectively.

The sorption of REEs is identified by the appearance of their typical signals. The most significant for $\operatorname{Pr}(\mathrm{III})$ appeared around $118 \mathrm{eV}(\operatorname{Pr} 4 \mathrm{~d}), 221$, and $234 \mathrm{eV}\left(\operatorname{Pr} 4 \mathrm{p}_{3 / 2}\right.$ and $\left.\operatorname{Pr} 2 \mathrm{p}_{1 / 2}\right), 308 \mathrm{eV}(\operatorname{Pr} 4 \mathrm{~s}), 934$, and $955 \mathrm{eV}\left(\operatorname{Pr} 3 \mathrm{~d}_{5 / 2}\right.$ and $\left.\operatorname{Pr} 3 \mathrm{~d}_{3 / 2}\right)$, and 1245/1340 eV $\left(\operatorname{Pr} 3 p_{3 / 2}\right.$ and $\left.\operatorname{Pr} 3 p_{1 / 2}\right)$. In the case of Tm-loaded sorbent, the typical signals were identified at $32 \mathrm{eV}\left(\operatorname{Tm} 5 \mathrm{p}_{1 / 2}\right), 178 \mathrm{eV}(\operatorname{Tm} 4 \mathrm{~d}), 335 \mathrm{eV}\left(\operatorname{Tm} 4 \mathrm{p}_{3 / 2}\right)$, and $473 \mathrm{eV}(\operatorname{Tm} 4 \mathrm{~s})$.

High-resolution XPS spectra are summarized in Table S5. Table S5b-d compare the respective spectra for APEI and P2-APEI as well as the spectra for the functionalized sorbent after $\operatorname{Pr}(\mathrm{III})$ and $\mathrm{Tm}(\mathrm{III})$ sorption. Table S5a shows that the profiles of the C 1s signal was significantly affected by the functionalization of the raw material and even more by the binding of $\operatorname{Pr}(\mathrm{III})$ and $\operatorname{Tm}(\mathrm{III})$ : more specifically, the contribution of $\mathrm{C}-\mathrm{C}$ signal is reinforced. Table S5b shows that the sorption of REEs was followed by the reinforcement of the contribution of the signal at $\sim 530 \mathrm{eV}$ (assigned to $\mathrm{P}=\mathrm{O}$ ) after metal binding, while the $\mathrm{C}=\mathrm{O}$ signal was reduced; the contribution of carboxylate groups to metal uptake cannot be neglected. In the case of $\mathrm{N}$ 1s (Table S5c), the peak at BE $\sim 399.4 \mathrm{eV}$ (associated with $\mathrm{N}-\mathrm{C}=\mathrm{O}$, $\mathrm{N}-\mathrm{H}, \mathrm{N}-\mathrm{C}$ ) apparently disappeared, while the $\mathrm{R}=\mathrm{N}-\mathrm{R}$ band was increased (the intensity of the other band at $\sim 400.5 \mathrm{eV}$ decreases). The $\mathrm{N}$-based functional groups are involved in metal binding. Table S5d confirms the changes in the environment of P-bearing groups after the sorption of REEs. Table S5e summarizes the assignments and BEs of C 1s, O 1s, N $1 \mathrm{~s}$, and P 2p signals (representative of the most relevant functional groups identified on the two sorbents) as well as their atomic fractions. One of the first pieces of information derived from this table is the relative stability of the BEs: the $\triangle \mathrm{BEs}$ did not exceed $0.3 \mathrm{eV}$ in most cases. The most significant differences are reported in terms of atomic fractions and 
the appearance/disappearance of deconvoluted peaks. The atomic fractions confirm the conclusions raised while observing the changes in HRES XPS spectra.

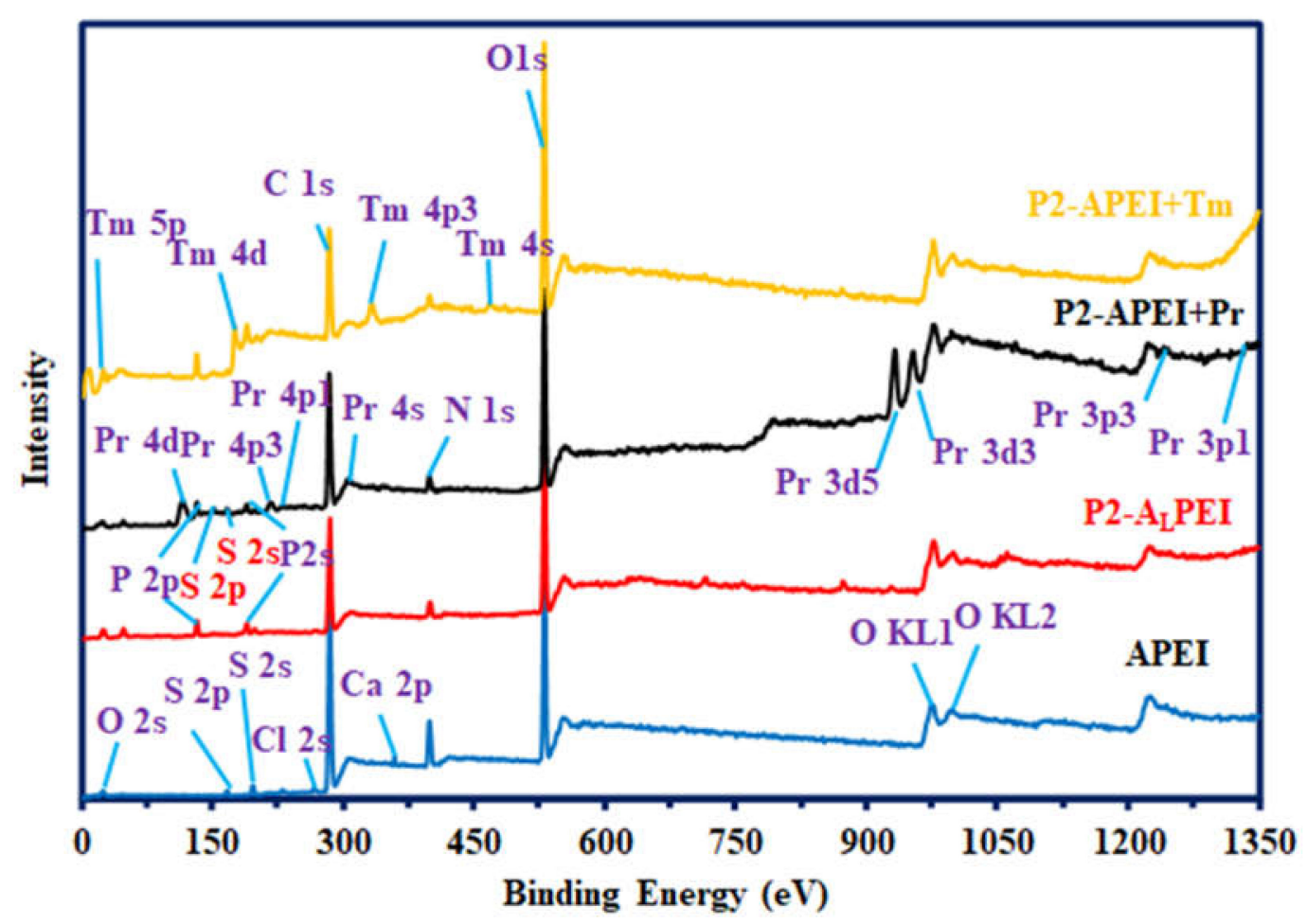

Figure 3. XPS survey scans of APEI and P2-APEI beads (including after Pr(III) and Tm(III) sorption).

\subsubsection{Elemental Analysis and $\mathrm{pH}_{\mathrm{PZC}}$}

Table S6 shows the elemental analysis of APEI before and after functionalization. The chemical modification (epichlorohydrin activation and grafting of triethyl phosphite) led to a decrease in the relative fraction of nitrogen in the sorbent: from $4.18 \mathrm{mmol} \mathrm{N} \mathrm{g}{ }^{-1}$ to $2.76 \mathrm{mmol} \mathrm{N} \mathrm{g}{ }^{-1}$. The phosphorylation allowed a phosphorus content close to $2.58 \mathrm{mmol} \mathrm{g}^{-1}$ to be reached. This means that about $93.5 \%$ of N-based groups were grafted with triethyl phosphite: the functionalization procedure was highly efficient.

The $\mathrm{pH}_{\mathrm{PZC}}$, approached by the $\mathrm{pH}$-drift method, was strongly reduced by the chemical modification from 6.6 for APEI to 2.4 for P2-APEI (Figure S5). These values can be explained by the reactive groups present at the surface of the sorbent: APEI bears primary, secondary, and tertiary amine groups from PEI (pKa: 4.5, 6.7, and 11.6, respectively [53]) and carboxylic groups (mannuronic and guluronic groups from alginate with $\mathrm{pK}_{\mathrm{a}}: 3.38$ and 3.65, respectively [54]). Additionally, P2-APEI holds phosphonate moieties with $\mathrm{pK}_{\mathrm{a}}$ values supposed to be much higher [55], depending on the substituting groups on the phosphonate entity. The order of magnitude of the $\mathrm{pH}_{\mathrm{PZC}}$ is consistent with the value reported for polyaminophosphonic acid-functionalized poly(glycidyl methacrylate) (i.e., 2.69) [28] and a composite obtained by high-energy ball milling of magnetite with aminophosphonic derivative of PGMA (i.e., 2.83) [56]. The functionalized sorbent will be deprotonated on a wider $\mathrm{pH}$ range than the raw material: the repulsion of metal cations is expected to be decreased for P2-APEI in weakly acidic solutions.

\subsection{Sorption Studies on Synthetic Solutions \\ 3.2.1. $\mathrm{pH}$ Effect}

Figure 4 compares the effect of equilibrium $\mathrm{pH}$ on the sorption properties of APEI and P2-APEI (initial $\mathrm{pH}$ varies between 1 and 5) for both $\operatorname{Pr}(\mathrm{III})$ and $\mathrm{Tm}(\mathrm{III})$. The duplication of experiments shows the good reproducibility of sorption performance. In the case of APEI, 
the sorption capacity linearly increased with the $\mathrm{pH}$; however, under selected experimental conditions, the improvement in sorption performance remained limited: from 0.025 to $0.082 \mathrm{mmol} \mathrm{Pr} \mathrm{g}^{-1}$ and from 0.013 to $0.051 \mathrm{mmol} \mathrm{Tm} \mathrm{g}^{-1}$. The effect of $\mathrm{pH}$ on the sorption of REEs was more marked in the case of P2-APEI. While the sorption capacities were of the same order of magnitude as APEI at $\mathrm{pH}$ close to 1 (i.e., $0.053 \mathrm{mmol} \mathrm{Pr} \mathrm{g}{ }^{-1}$ and $0.03 \mathrm{mmol} \mathrm{Tm}^{-1}$ ), the binding strongly increased with the $\mathrm{pH}$ : up to $0.36 \mathrm{mmol} \mathrm{Pr}^{-1}$ and $0.27 \mathrm{mmol} \mathrm{Tm} \mathrm{g}^{-1}$ (i.e., seven and nine times the reference values for APEI).
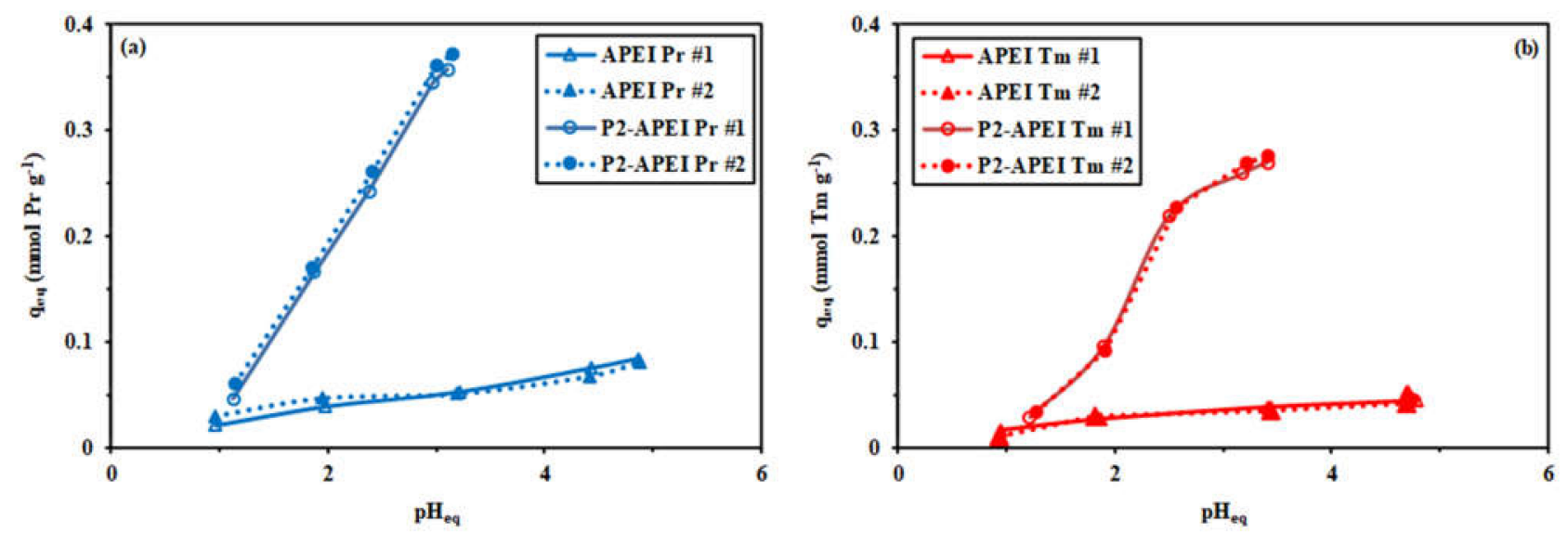

Figure 4. Effect of equilibrium $\mathrm{pH}$ on the sorption of $\operatorname{Pr}(\mathrm{III})$ (a) and $\operatorname{Tm}(\mathrm{III})$ (b) using APEI and P2-APEI sorbents $\left(\mathrm{C}_{0}: 50 \mathrm{mg} \mathrm{L}^{-1}\right.$; Sorbent dosage, SD: $1 \mathrm{~g} \mathrm{~L}^{-1}$; Contact time: $48 \mathrm{~h}$; $\mathrm{T}: 22 \pm 1{ }^{\circ} \mathrm{C}$; duplicate experiments).

The progressive deprotonation of the sorbents increases their sorption efficiency; this is especially significant in the case of P2-APEI because of the differences in $\mathrm{pH}_{\mathrm{PZC}}$ values and the presence of phosphonate groups. In acidic $\mathrm{pH}$ solutions, alginate carboxyl groups are under their acidic form, while all amine groups are also protonated: cations are repulsed. On the other hand, for P2-APEI, the positive charge at the surface of the sorbent tends to decrease, favoring metal binding; above $\mathrm{pH} 2.4$, the surface of the sorbent becomes progressively negative. Precisely, the sorption of Tm(III) drastically increases above $\mathrm{pH} 2.5$.

The speciation diagrams for $\operatorname{Pr}(\mathrm{III})$ and $\mathrm{Tm}(\mathrm{III})$ are reported in Figure S6. At $\mathrm{pH}$ below 3 , the predominant species were the sulfate complexes $\left(\operatorname{REE}\left(\mathrm{SO}_{4}\right)^{+}\right.$and $\left.\operatorname{REE}\left(\mathrm{SO}_{4}\right)_{2}^{-}\right)$: the contribution of the anionic species decreased with increasing the $\mathrm{pH}$. The protonated species (free $\mathrm{REE}^{3+}$ and $\mathrm{REE}\left(\mathrm{SO}_{4}\right)^{+}$) also predominated over the whole $\mathrm{pH}$ range. Anionic species at $\mathrm{pH} 1$ can be bound onto protonated amine groups by electrostatic attraction. The increase in $\mathrm{S}$ content on the sorbent after $\mathrm{pH}$ sorption means that REE sulfate species are involved in metal binding. Between $\mathrm{pH} 2$ and $\mathrm{pH} 4$, the fraction of free REE(III) progressively increased and predominated over $\mathrm{pH} 3.8$. This may be correlated to the strong enhancement in sorption property at $\mathrm{pH}$ above 2, especially for P2-APEI.

Figure $\mathrm{S} 6$ follows the $\mathrm{pH}$ variation during metal sorption for APEI and P2-APEI sorbents. The differences in acid-base properties of the sorbents were consistent with those variations: APEI tended to slightly increase the $\mathrm{pH}$ of the solution in the range $\mathrm{pH}_{0} 2-4$ (maximum variation: $+0.7 \mathrm{pH}$ unit) while $\mathrm{P} 2$-APEI progressively decreased the $\mathrm{pH}$ of the solution (by up to $-1.6 /-1.85$ ). This is another illustration of the difference in the sorption mechanisms for the two sorbents.

\subsubsection{Uptake Kinetics}

The uptake kinetics are represented in Figures 5 and 6 . Under selected experimental conditions $\left(\mathrm{C}_{0}: 50 \mathrm{mg} \mathrm{L}^{-1}\right.$ and SD: $\left.0.25 \mathrm{~g} \mathrm{~L}^{-1}\right)$, the sorption process was fast enough to reach equilibrium within $30 \mathrm{~min}$ of contact (Figure 5) in mono-component solutions for both APEI and P2-APEI sorbents. Similar trends were observed for $\operatorname{Pr}(\mathrm{III})$ and $\mathrm{Tm}$ (III) uptake from binary solutions. As expected, the enhanced affinity of P2-APEI for REEs 
allowed for a substantial increase in the sorption capacity and efficiency (illustrated by lower residual concentrations).

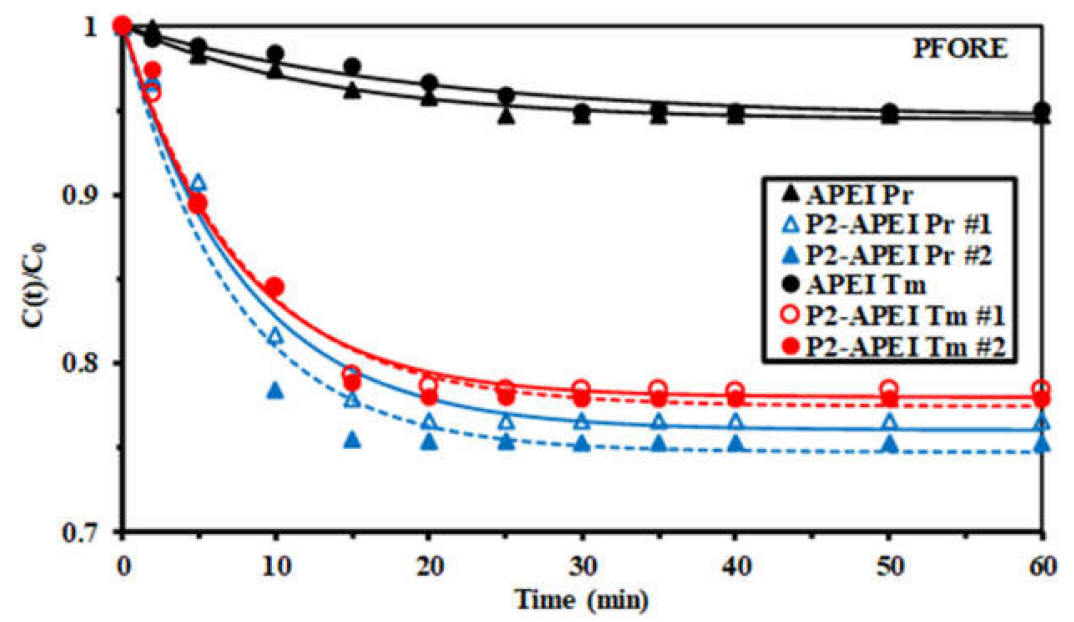

Figure 5. $\mathrm{Pr}(\mathrm{III})$ and $\mathrm{Tm}(\mathrm{III})$ uptake kinetics using APEI and P2-APEI sorbents (duplicate experiments) $\left(\mathrm{C}_{0}: 50 \mathrm{mg} \mathrm{L}^{-1}\right.$; Sorbent dosage, SD: $0.25 \mathrm{~g} \mathrm{~L}^{-1} ; \mathrm{pH}_{0}: 5 ; \mathrm{pH}_{\mathrm{eq}}: 4.87$ and 4.62 for APEI for $\operatorname{Pr}(\mathrm{III})$ and Tm(III), respectively; 3.24-3.12 for Pr(III) and 3.44-3.47 for Tm(III) with P2-APEI; T: $22 \pm 1{ }^{\circ} \mathrm{C}$; solid lines: modeling with PFORE).

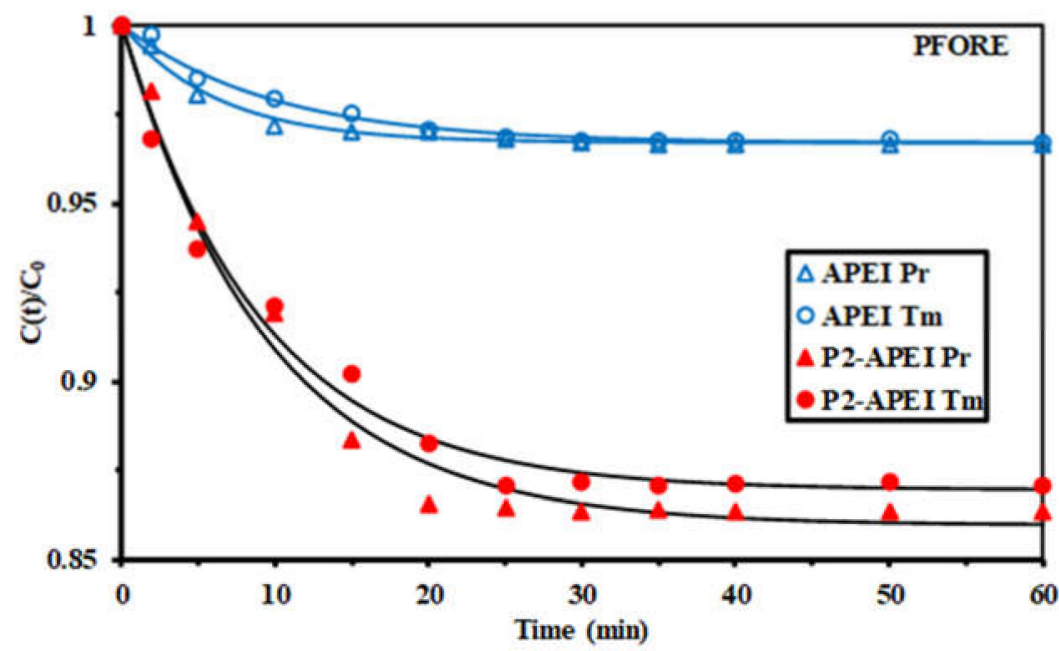

Figure 6. $\operatorname{Pr}(\mathrm{III})$ and $\mathrm{Tm}(\mathrm{III})$ uptake kinetics using APEI and P2-APEI sorbents from binary solutions $\left(\mathrm{C}_{0}: 50 \mathrm{mg} \mathrm{L}^{-1}\right.$; Sorbent dosage, SD: $0.25 \mathrm{~g} \mathrm{~L}^{-1} ; \mathrm{pH}_{0}: 5 ; \mathrm{pH}_{\mathrm{eq}}: 4.87$ and 4.62 for APEI for $\operatorname{Pr}(\mathrm{III})$ and Tm(III), respectively; 3.24-3.12 for Pr(III) and 3.44-3.47 for Tm(III) with P2-APEI; T: $22 \pm 1{ }^{\circ} \mathrm{C}$; solid lines: modeling with PFORE).

Sorption capacity for P2-APEI was over four times the value reached for APEI. The kinetic profiles were fitted with selected models (reported in Table S1) [57,58]. The comparison of determination coefficients and Akaike information criterion (AIC, Table S1b) for the different equations showed that the best fits were obtained with the pseudo-first order rate equation (Tables 1 and 2). 
Table 1. Pr(III) uptake kinetics using APEI and P2-APEI sorbents—fitting parameters for the PFORE, PSORE, and RIDE models.

\begin{tabular}{|c|c|c|c|c|}
\hline \multirow{3}{*}{ Model } & \multirow{3}{*}{ Parameter } & \multicolumn{3}{|c|}{ Sorbent } \\
\hline & & \multirow{2}{*}{ APEI } & \multicolumn{2}{|c|}{ P2-APEI } \\
\hline & & & 1st Run & 2nd Run \\
\hline Exp. & $q_{\text {eq,exp }}\left(\mathrm{mmol} \mathrm{g}^{-1}\right)$ & 0.0795 & 0.357 & 0.348 \\
\hline \multirow[t]{4}{*}{ PFORE } & $q_{1, \text { calc }}\left(\mathrm{mmol} \mathrm{g}^{-1}\right)$ & 0.0828 & 0.365 & 0.356 \\
\hline & $k_{1} \times 10^{2}\left(\min ^{-1}\right)$ & 7.45 & 12.8 & 14.0 \\
\hline & $R^{2}$ & 0.980 & 0.985 & 0.973 \\
\hline & AIC & -133 & -102 & -94 \\
\hline \multirow[t]{4}{*}{ PSORE } & $q_{2, \text { calc }}\left(\mathrm{mmol} \mathrm{g}^{-1}\right)$ & 0.101 & 0.418 & 0.405 \\
\hline & $k_{2} \times 10\left(\mathrm{~L} \mathrm{mmol}^{-1} \mathrm{~min}^{-1}\right)$ & 7.95 & 3.81 & 4.35 \\
\hline & $\mathrm{R}^{2}$ & 0.965 & 0.956 & 0.938 \\
\hline & AIC & -126 & -90 & -85 \\
\hline \multirow[t]{3}{*}{ RIDE } & $\mathrm{D}_{\mathrm{e}} \times 10^{8}\left(\mathrm{~m}^{2} \min ^{-1}\right)$ & 3.66 & 4.91 & 5.30 \\
\hline & $\mathrm{R}^{2}$ & 0.960 & 0.960 & 0.945 \\
\hline & AIC & -124 & -92 & -87 \\
\hline
\end{tabular}

Table 2. Tm(III) uptake kinetics using APEI and P2-APEI sorbents—fitting parameters for the PFORE, PSORE, and RIDE models.

\begin{tabular}{|c|c|c|c|c|}
\hline \multirow{3}{*}{ Model } & \multirow{3}{*}{ Parameter } & \multicolumn{3}{|c|}{ Sorbent } \\
\hline & & \multirow{2}{*}{ APEI } & \multicolumn{2}{|c|}{ P2-APEI } \\
\hline & & & 1st Run & 2nd Run \\
\hline Exp. & $q_{\text {eq,exp }}\left(\mathrm{mmol} \mathrm{g}^{-1}\right)$ & 0.0608 & 0.271 & 0.269 \\
\hline \multirow[t]{4}{*}{ PFORE } & $q_{1, \text { calc }}\left(\mathrm{mmol} \mathrm{g}^{-1}\right)$ & 0.0666 & 0.276 & 0.275 \\
\hline & $k_{1} \times 10^{2}\left(\min ^{-1}\right)$ & 5.09 & 13.5 & 12.7 \\
\hline & $\mathrm{R}^{2}$ & 0.964 & 0.992 & 0.985 \\
\hline & AIC & -130 & -113 & -104 \\
\hline \multirow[t]{4}{*}{ PSORE } & $q_{2, \text { calc }}\left(\mathrm{mmol} \mathrm{g}^{-1}\right)$ & 0.085 & 0.313 & 0.315 \\
\hline & $k_{2} \times 10\left(\mathrm{~L} \mathrm{mmol}^{-1} \mathrm{~min}^{-1}\right)$ & 5.67 & 5.64 & 5.06 \\
\hline & $R^{2}$ & 0.953 & 0.969 & 0.960 \\
\hline & AIC & -125 & -98 & -93 \\
\hline \multirow[t]{3}{*}{ RIDE } & $\mathrm{D}_{\mathrm{e}} \times 10^{8}\left(\mathrm{~m}^{2} \mathrm{~min}^{-1}\right)$ & 2.74 & 5.16 & 4.92 \\
\hline & $\mathrm{R}^{2}$ & 0.933 & 0.975 & 0.964 \\
\hline & AIC & -122 & -101 & -95 \\
\hline
\end{tabular}

Figure S8 shows the modeling of kinetic profiles with alternative models (PSORE and RIDE). This was also confirmed by the close values for calculated equilibrium sorption capacities and experimental values: overestimation reached $2 \%$ for P2-APEI and $4 \%$ for APEI. The solid lines in Figure 5 represent the PFORE fitting applied to the experimental profiles as confirmation of the appropriateness of the model to describe the transfer of the REEs onto the sorbents. The PFORE is generally associated with a physical sorption mechanism. However, Hubbe et al. [59] pointed out the importance of selecting appropriate experimental conditions for justifying the relevant interpretations of mathematical fits. They also demonstrated that the fitting of kinetic profiles was frequently correlated to sorption processes controlled by resistance to intraparticle diffusion. The apparent rate coefficient (i.e., $\mathrm{k}_{1}$ ) was more than doubled for P2-APEI compared with the reference value (i.e., APEI) for both $\operatorname{Pr}(\mathrm{III})$ and $\mathrm{Tm}(\mathrm{III})$. The faster kinetics of P2-APEI can be correlated to the more open surface structure observed in the SEM pictures (Table S2). Table S7 shows the surface and crosscut section SEM pictures (with their relevant semi-quantitative EDX analyses). Metal sorption slightly changes the surface of APEI beads with the formation of additional porosity; internal porosity was not affected. In the case of P2-APEI and the surface morphology was not significantly changed. The semi-quantitative analyses 
confirmed the higher sorption of REEs in P2-APEI. It is noteworthy that the distribution of elements (REE, N) was more homogeneous between the surface and crosscut section for P2-APEI for $\operatorname{Tm}$ (III) than for $\operatorname{Pr}(\mathrm{III})$. It is noteworthy that in this case, the $\operatorname{Pr}(\mathrm{III})$ content was remarkably lower in the crosscut section for P2-APEI.

Although the RIDE (resistance to intraparticle diffusion, the so-called Crank equation [57]) model, does not fit experimental profiles as well as the PFORE model, the equation allows an approximate value of the effective diffusivity (i.e., $\mathrm{D}_{\mathrm{e}}$ ) to be calculated. As expected, the diffusivity slightly increased with the functionalization of the sorbent from $3.7 \times 10^{-8}$ to $5.1 \times 10^{-8} \mathrm{~m}^{2} \mathrm{~min}^{-1}$ for $\operatorname{Pr}(\mathrm{III})$, and from $2.7 \times 10^{-8}$ to $5.0 \times 10^{-8} \mathrm{~m}^{2}$ $\mathrm{min}^{-1}$ for $\mathrm{Tm}$ (III). Praseodymium was characterized by a larger size of hydrated ion (i.e., $\mathrm{r}_{\mathrm{h}}=1.179 \AA$ ) compared with $\mathrm{Tm}(\mathrm{III})$ (i.e., $\mathrm{r}_{\mathrm{h}}=0.994 \AA$ ) [60]. This is not enough to affect the mass transfer properties in the sorbents. These values of $D_{e}$ were of the same order of magnitude as the self-diffusion of $\operatorname{Pr}(\mathrm{III})$ and $\mathrm{Tm}$ (III) in water (i.e., $3.7 \times 10^{-8}$ and $3.5 \times 10^{-8} \mathrm{~m}^{2} \mathrm{~min}^{-1}$, respectively [61]). This means that the resistance to intraparticle diffusion does not play a critical role in the control of uptake kinetics. This is consistent with the fast sorption (equilibrium reached within $30 \mathrm{~min}$ ), despite the relatively large size of the beads (i.e., $2.8-2.9 \mathrm{~mm}$ ).

Similar trends were observed for uptake kinetics in binary solutions (Figure 6 and Table 3). The effective diffusivities were of the same order of magnitude than for mono-component solutions (ranging between $4.4 \times 10^{-8}$ and $6.7 \times 10^{-8} \mathrm{~m}^{2} \mathrm{~min}^{-1}$ ). It is noteworthy that the sorption capacities at equilibrium in binary solutions were lower than the values reported (for the same initial metal concentration) in the case of monocomponent solutions. The cumulative sorption capacity was close to $0.38 \mathrm{mmol} \mathrm{REE} \mathrm{g}^{-1}$ $\left(0.196 \mathrm{mmol} \mathrm{Pr} \mathrm{g}^{-1}+0.186 \mathrm{mmol} \mathrm{Tm} \mathrm{g}^{-1}\right)$ while for individual metal solutions, the sorption capacities were $0.36 \mathrm{mmol} \mathrm{Pr} \mathrm{g}^{-1}$ and $0.275 \mathrm{mmol} \mathrm{Tm} \mathrm{g}^{-1}$ for PFORE modeling of REE sorption using P2-APEI. The competition effect decreased the global sorption performance. This was also shown by the decrease in the apparent rate coefficient by one order of magnitude. The two metals were supposed to be bound on the same reactive groups. The cumulative sorption capacity was far below the maximum sorption capacities (see below); this means that the sorbent was not saturated. Both the global sorption capacity and the kinetic rates were depreciated by the competitor effect.

Table 3. Pr(III) and Tm(III) uptake kinetics using APEI and P2-APEI sorbents from binary solutions-fitting parameters for the PFORE, PSORE, and RIDE models.

\begin{tabular}{|c|c|c|c|c|c|}
\hline \multirow{3}{*}{ Model } & \multirow{3}{*}{ Parameter } & \multicolumn{4}{|c|}{ Sorbent } \\
\hline & & \multicolumn{2}{|c|}{ APEI } & \multicolumn{2}{|c|}{ P2-APEI } \\
\hline & & $\operatorname{Pr}(\mathrm{III})$ & $\operatorname{Tm}($ III) & $\operatorname{Pr}($ III) & $\operatorname{Tm}(I I I)$ \\
\hline Exp. & $q_{\mathrm{eq}, \exp }\left(\mathrm{mmol} \mathrm{g}^{-1}\right)$ & 0.047 & 0.046 & 0.190 & 0.184 \\
\hline \multirow[t]{4}{*}{ PFORE } & $q_{1, \text { calc }}\left(\mathrm{mmol} \mathrm{g}^{-1}\right)$ & 0.047 & 0.047 & 0.196 & 0.186 \\
\hline & $k_{1} \times 10^{2}\left(\min ^{-1}\right)$ & 1.59 & 1.02 & 1.05 & 1.10 \\
\hline & $R^{2}$ & 0.987 & 0.988 & 0.988 & 0.988 \\
\hline & AIC & -154 & -154 & -119 & -123 \\
\hline \multirow[t]{4}{*}{ PSORE } & $q_{2, \text { calc }}\left(\mathrm{mmol} \mathrm{g}^{-1}\right)$ & 0.053 & 0.055 & 0.228 & 0.212 \\
\hline & $\begin{array}{c}k_{2} \times 10\left(\mathrm{~L} \mathrm{mmol}^{-1}\right. \\
\left.\min ^{-1}\right)\end{array}$ & 39.7 & 22.5 & 5.62 & 6.91 \\
\hline & $\mathrm{R}^{2}$ & 0.974 & 0.978 & 0.968 & 0.982 \\
\hline & AIC & -145 & -145 & -107 & -118 \\
\hline \multirow[t]{3}{*}{ RIDE } & $\mathrm{D}_{\mathrm{e}} \times 10^{8}\left(\mathrm{~m}^{2} \min ^{-1}\right)$ & 6.72 & 4.55 & 4.43 & 4.54 \\
\hline & $\mathrm{R}^{2}$ & 0.976 & 0.978 & 0.970 & 0.985 \\
\hline & AIC & -149 & -147 & -108 & -122 \\
\hline
\end{tabular}

The sorption of $\operatorname{Pr}(\mathrm{III})$ and $\mathrm{Tm}(\mathrm{III})$ controlled for both APEI and P2-APEI is not controlled by the resistance to intraparticle diffusion. The kinetic profiles can be described by the PFORE. This result was consistent with the conclusions raised for other deriva- 
tives of APEI (quaternized, sulfonated, amidoximated) in the sorption of different metal ions $[44-46,62,63]$.

\subsubsection{Sorption Isotherms}

Figure 7 shows the sorption isotherms for $\operatorname{Pr}(\mathrm{III})$ and $\mathrm{Tm}(\mathrm{III})$ using APEI and P2-APEI sorbents at $\mathrm{pH}_{0} 5$. The duplication of the sorption isotherm for P2-APEI confirmed the good reproducibility of sorption performance. Equilibrium $\mathrm{pH}$ value varied between 4.7 and 4.8 for APEI but decreased to 3.1-3.5 for P2-APEI, consistently with the results reported for the study of the $\mathrm{pH}$ effect.

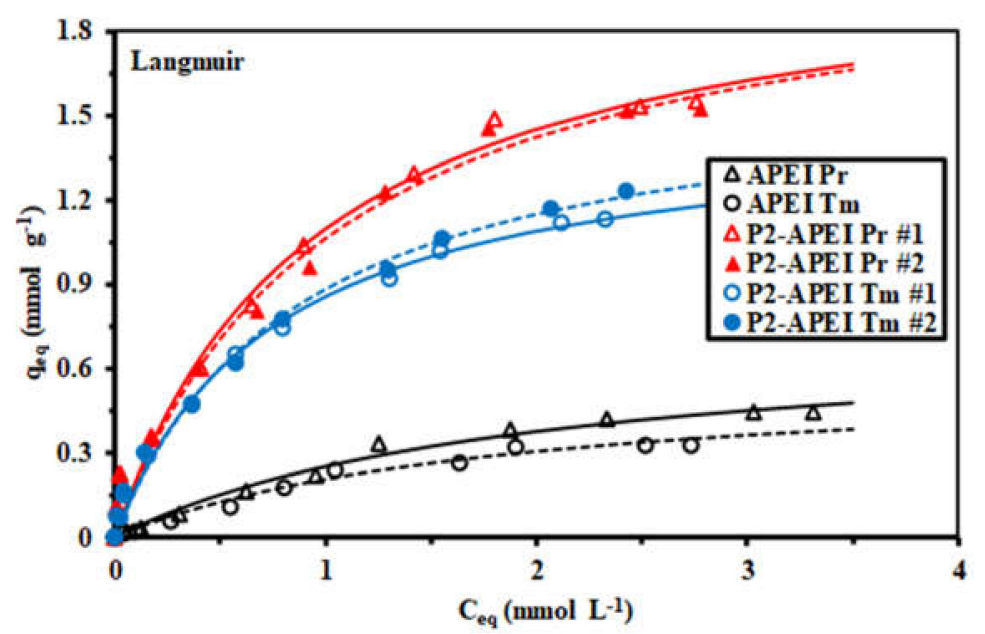

Figure 7. $\operatorname{Pr}(\mathrm{III})$ and $\mathrm{Tm}(\mathrm{III})$ sorption isotherms using APEI and P2-APEI (duplicate experiments) $\left(\mathrm{C}_{0}: 10-500 \mathrm{mg} \mathrm{L}^{-1}\right.$; Sorbent dosage, SD: $0.5 \mathrm{~g} \mathrm{~L}^{-1} ; \mathrm{pH}_{0}$ : 5; $\mathrm{pH}_{\mathrm{eq}}$ : 4.81-4.7 and 4.79-4.72 for APEI for $\operatorname{Pr}(\mathrm{III})$ and $\operatorname{Tm}(\mathrm{III})$, respectively; 3.27-3.08 for Pr(III) and 3.54-3.39 for Tm(III) with P2-APEI; time: $48 \mathrm{~h}$; T: $22 \pm 1{ }^{\circ} \mathrm{C}$; solid lines: modeling with the Langmuir equation).

The maximum sorption capacities reached $0.45 \mathrm{mmol} \mathrm{Pr}^{-1}$ and $0.33 \mathrm{mmol} \mathrm{Tm}^{-1}$ for APEI. The functionalization strongly increased the sorption capacities up to $1.54 \mathrm{mmol}$ $\operatorname{Pr~}^{-1}$ and $1.19 \mathrm{mmol} \mathrm{Tm} \mathrm{g}^{-1}$ (i.e., about three times). The highest sorption capacities for $\operatorname{Pr}(\mathrm{III})$ compared with Tm(III) showed the preference of the sorbent for light vs. heavy REE. The solution electronegativity of REEs can be ranked according to $\operatorname{Pr}$ (III) $(3.037)<\operatorname{Tm}$ (III) (3.503). Marcus [61] summarized the polarizability of elements using different sources that systematically report higher polarizability for $\operatorname{Pr}(\mathrm{III})$ than for $\operatorname{Tm}(\mathrm{III})$, combined with the lowest hydrated radius of $\operatorname{Tm}(\mathrm{III})(0.994 \AA)$ than that of $\operatorname{Pr}(\mathrm{III})(1.179 \AA)$, thulium may be considered a stronger acid than praseodymium, according to Pearson's rules (hard and soft acid-base theory,(HSAB) [64]). Iftekhar et al. [65] compared the sorption of a series of REEs on biopolymer-layered double hydroxides LDH hybrid nanocomposites and they concluded that small ionic radii enhanced the sorption; this is contradictory to the trend found with P2-APEI (ionic radii: $1.179 \AA$ for $\operatorname{Pr}(\mathrm{III})$ and $1.052 \AA$ for $\mathrm{Tm}(\mathrm{III})$ ). Phosphonate and amine groups are both considered hard bases [66,67], which are supposed to be more reactive with hard acids. In the case of strong cation exchange resin Dowex 50, Surls and Choppin [68] obtained a linear correlation between the ion-exchange sorbability (the energy of formation of the complex) and the ionic conductance of the REEs (and $\mathrm{Am}+\mathrm{Cu}$ ). Marcus [61] reported the conductivity of $\operatorname{Pr}(\mathrm{III})$ and $\mathrm{Tm}$ (III) to be 208.8 and $196.2 \mathrm{~cm}^{2} \Omega^{-1} \mathrm{~mol}^{-1}$, respectively (reciprocal trend than the hydrated radius).

The shape of the curves was characterized by a steep initial increase in the sorption capacities followed by a saturation plateau. This shape is consistent with the asymptotic trend of the Langmuir equation compared with the Freundlich equation, which is assimilated to a power-type function. These conventional models (described in Table S1b) are commonly used for describing sorption isotherm profiles. The Langmuir equation supposes that the sorption occurs as a monolayer at the surface of the sorbent with no interactions between 
the sorbed molecules. Furthermore, the energies involved in the sorption are considered homogeneous. The co-existence of different reactive groups (i.e., amine, carboxylate, and phosphonate) does not appear to create heterogeneities in terms of interaction with REEs. The Sips equation is a combination of the Langmuir and the Freundlich equation, which includes a third-adjustable parameter that is supposed to improve mathematical fitting (Figure S9).

Actually, Table 4 shows that there is no clear evidence for better fitting experimental profiles with the Sips equation (this depends on the couple metal/sorbent). The Langmuir equation, which is more mechanistic than the mathematical Sips function, was preferred for simulating isotherms in Figure 7. It is noteworthy that the models well fit the isotherm profile for residual concentrations higher than $0.2 \mathrm{mmol} \mathrm{L}^{-1}$, but tended to underestimate the sorption capacities for the concentrations below $0.0 \mathrm{mmol} \mathrm{L}^{-1}$. The comparison of $\mathrm{q}_{\mathrm{m}, \mathrm{L}}$ and $\mathrm{q}_{\mathrm{m} \text {,exp }}$ showed that the model overestimated the experimental value of the sorption capacity at saturation by $68-76 \%$ for APEI, $\sim 40 \%$, and $\sim 33 \%$ for P2-APEI and $\operatorname{Pr}(\mathrm{III}) / \mathrm{Tm}(\mathrm{IIII})$, respectively. The affinity coefficient (i.e., $\mathrm{b}_{\mathrm{L}}$ ) was slightly higher for P2-APEI (i.e., 0.98 to $1.33 \mathrm{~L} \mathrm{mmol}^{-1}$ ) than for APEI (i.e., $0.50-0.54 \mathrm{~L} \mathrm{mmol}^{-1}$ ). The affinity coefficients of the sorbents for $\mathrm{Tm}$ (III) were systematically a little better for $\operatorname{Tm}(\mathrm{III})$ than for $\operatorname{Pr}(\mathrm{III})$. The initial slope of the curve is described by the term $\mathrm{q}_{\mathrm{m}, \mathrm{L}} \times \mathrm{b}_{\mathrm{L}}\left(\mathrm{L} \mathrm{g}^{-1}\right)$ : 0.38 and $0.26 \mathrm{~L} \mathrm{~g}^{-1}$ for $\operatorname{Pr}(\mathrm{III})$ and Tm(III) in the case of APEI, and 2.18 and $1.95 \mathrm{~L} \mathrm{~g}^{-1}$ for P2-APEI.

Table 4. Pr(III) and Tm(III) sorption isotherms using APEI and P2-APEI sorbents-fitting parameters for the Langmuir, Freundlich, and Sips equations.

\begin{tabular}{|c|c|c|c|c|c|c|c|}
\hline \multirow{3}{*}{ Model } & \multirow{3}{*}{ Parameter } & \multicolumn{4}{|c|}{ Sorbent } & & \\
\hline & & \multicolumn{2}{|c|}{ APEI } & \multicolumn{4}{|c|}{ P2-APEI } \\
\hline & & $\operatorname{Pr}(\mathrm{III})$ & $\operatorname{Tm}(\mathrm{III})$ & $\begin{array}{c}\operatorname{Pr}(\mathrm{III}) \\
\# 1\end{array}$ & $\begin{array}{l}\operatorname{Pr}(\mathrm{III}) \\
\quad \# 2\end{array}$ & $\begin{array}{c}\operatorname{Tm}(\mathrm{III}) \\
\# 1\end{array}$ & $\begin{array}{c}\operatorname{Tm}(\mathrm{III}) \\
\# 2\end{array}$ \\
\hline Exp. & $q_{\mathrm{m}, \exp }$ & 0.448 & 0.331 & 1.554 & 1.525 & 1.135 & 1.230 \\
\hline \multirow[t]{4}{*}{ Langmuir } & $q_{\mathrm{m}, \mathrm{L}}$ & 0.752 & 0.584 & 2.14 & 2.151 & 1.494 & 1.645 \\
\hline & $\mathrm{b}_{\mathrm{L}}$ & 0.502 & 0.539 & 1.05 & 0.980 & 1.334 & 1.153 \\
\hline & $\mathrm{R}^{2}$ & 0.988 & 0.983 & 0.990 & 0.989 & 0.996 & 0.994 \\
\hline & AIC & -81 & -84 & -55 & -54 & -70 & -67 \\
\hline \multirow[t]{4}{*}{ Freundlich } & $k_{\mathrm{F}}$ & 0.235 & 0.191 & 1.02 & 0.998 & 0.794 & 0.820 \\
\hline & $\mathrm{n}_{\mathrm{F}}$ & 1.635 & 1.580 & 2.105 & 2.060 & 2.104 & 1.992 \\
\hline & $\mathrm{R}^{2}$ & 0.968 & 0.966 & 0.984 & 0.985 & 0.994 & 0.995 \\
\hline & AIC & -71 & -76 & -52 & -53 & -70 & -71 \\
\hline \multirow[t]{5}{*}{ Sips } & $q_{\mathrm{m}, \mathrm{S}}$ & 0.540 & 0.392 & 2.867 & 3.161 & 2.269 & 2.749 \\
\hline & $\mathrm{b}_{\mathrm{S}}$ & 0.922 & 1.21 & 0.597 & 0.488 & 0.572 & 0.447 \\
\hline & $\mathrm{n}_{\mathrm{S}}$ & 0.666 & 0.621 & 1.319 & 1.380 & 1.422 & 1.441 \\
\hline & $\mathrm{R}^{2}$ & 0.994 & 0.991 & 0.990 & 0.989 & 0.998 & 0.998 \\
\hline & AIC & -84 & -83 & -53 & -53 & -80 & -80 \\
\hline
\end{tabular}

Table 5 reports the $\operatorname{Pr}(\mathrm{III})$ and $\operatorname{Tm}(\mathrm{III})$ sorption characteristics for a series of alternative sorbents. Most of the studies investigated the sorption of REEs in the $\mathrm{pH}$ range of 3-5. Taking into account both the kinetic criterion (i.e., equilibrium time) and the maximum sorption capacity (i.e., $\mathrm{q}_{\mathrm{m}, \mathrm{L}}$ ), P2-APEI appeared to be one of the most efficient sorbent. The functionalized sorbent showed remarkably fast kinetics (20-30 min for reaching equilibrium) and outstanding sorption capacities ( $1.57 \mathrm{mmol} \mathrm{Tm} \mathrm{g}^{-1}$ and $\left.2.14 \mathrm{Pr} \mathrm{g}^{-1}\right)$. The most efficient sorbents showed comparable sorption capacity; for example, $2.08 \mathrm{mmol} \mathrm{Pr}^{-1}$ in the case of sulfonic resin D72, but at the expense of much slower kinetics (equilibrium $24 \mathrm{~h}$ ) [10]. In the case of Tm(III), the most competitive sorbent was Turbinaria conoides, with a sorption capacity that did not exceed $1.19 \mathrm{mmol} \mathrm{Tm} \mathrm{g}^{-1}$ and a longer required contact time (more than $3 \mathrm{~h}$ for reaching equilibrium). Therefore, P2-APEI appears to be a good compromise between sorption capacity and kinetic criteria and a promising sorbent for LREEs and HREEs. The main weakness of this sorbent consists of the relatively weak 
affinity coefficient (i.e., $\mathrm{b}_{\mathrm{L}} \sim 1-1.3 \mathrm{~L} \mathrm{mmol}^{-1}$ ), while the best other sorbents showed values close to 8.6 or $17.1 \mathrm{~L} \mathrm{mmol}^{-1}$.

Table 5. Comparison of the $\operatorname{Pr}(\mathrm{III})$ and $\operatorname{Tm}(\mathrm{III})$ sorption properties for alternative sorbents.

\begin{tabular}{|c|c|c|c|c|c|c|}
\hline Metal & Sorbent & $\mathrm{pH}$ & $\begin{array}{c}t_{\mathrm{eq}} \\
(\mathrm{min})\end{array}$ & $\begin{array}{c}q_{\mathrm{m}, \mathrm{L}} \\
\left(\mathrm{mmol} \mathrm{g}^{-1}\right)\end{array}$ & $\begin{array}{c}\mathrm{b}_{\mathrm{L}} \\
\left(\mathrm{L} \mathrm{mmol}^{-1}\right)\end{array}$ & Ref. \\
\hline \multirow[t]{10}{*}{$\operatorname{Pr}(\mathrm{III})$} & Pseudomonas aeruginosa & 5 & 240 & 0.94 & n.r. & [69] \\
\hline & D72 resin $\left(-\mathrm{SO}_{3} \mathrm{H}\right)$ & 3 & 1440 & 2.08 & 8.60 & [10] \\
\hline & Turbinaria conoides & 5 & 90 & 1.04 & 7.33 & {$[70]$} \\
\hline & T. conoides / polysulfone beads & 5 & 240 & 0.85 & 2.40 & [70] \\
\hline & Crab shell & 5 & 35 & 0.47 & 3.66 & [71] \\
\hline & Orange peel & 5 & 50 & 0.42 & 2.25 & [71] \\
\hline & Laminaria digitata beads & 4 & $\begin{array}{c}180(\mathrm{FD}) \\
1440(\mathrm{AD})\end{array}$ & 0.89 & 125.4 & [72] \\
\hline & Laminaria digitata foams & 4 & 1440 & 0.79 & 111.3 & {$[72]$} \\
\hline & APEI & 5 & 30 & 0.75 & 0.50 & This work \\
\hline & P2-APEI & 5 & 20 & 2.14 & 1.02 & This work \\
\hline \multirow[t]{6}{*}{$\operatorname{Tm}(\mathrm{III})$} & PAN-polyurethane foam & 7.5 & 40 & 0.0083 & 51.1 & [73] \\
\hline & Turbinaria conoides & 5 & 200 & 1.19 & 17.1 & [74] \\
\hline & T. conoides/polysulfone beads & 5 & 200 & 0.93 & 5.91 & [74] \\
\hline & $\begin{array}{l}\text { Zr-ion imprinted xanthan } \\
\text { gum-layered double hydroxide }\end{array}$ & 4 & 80 & 0.19 & 255.1 & [75] \\
\hline & APEI & 5 & 30 & 0.58 & 0.54 & This work \\
\hline & P2-APEI & 5 & 20 & 1.57 & 1.24 & This work \\
\hline
\end{tabular}

\subsubsection{Sorption Mechanism}

According to the data collected from $\mathrm{pH}_{\mathrm{pzc}}$ (deprotonation of the sorbent), EDX analysis (the presence of metal and S elements), FTIR analysis (presence of sulfate group, shifts of specific groups after sorption), and speciation diagrams (free metal and metal complex species), it is probable that metal binding occurs directly on free species and also through the binding of sulfate complexes. Various functional groups such as amines (primary, secondary, and tertiary), hydroxyls, carboxyl groups, and phosphates may be active binding sites. The binding mechanism involves the ion exchange of metal cation with $\mathrm{Ca}^{2+}$ or $\mathrm{H}^{+}$on carboxylic groups from alginate. On the other hand, chelation mechanisms contribute through the electron pairs on the $\mathrm{O}, \mathrm{N}$, and $\mathrm{P}$ functional groups. Scheme 2 shows the suggested structure reporting active functional groups. These groups can interact with positively charged metal ions (free $\mathrm{REE}^{3+}$ ) or complexes (i.e., sulfate complex: $\mathrm{REE}\left(\mathrm{SO}_{4}\right)^{+}$). Scheme 3 summarizes the tentative mechanisms involved in metal uptake.

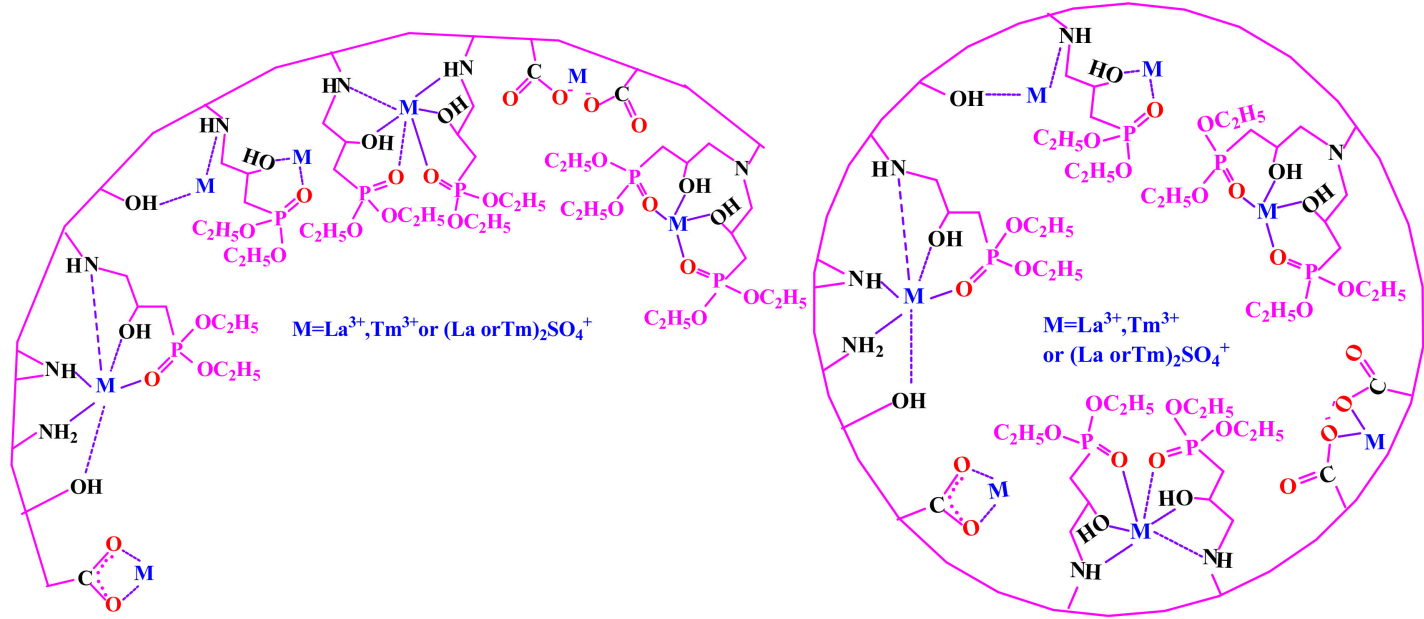

Scheme 3. Tentative mechanisms for metal sorption. 


\subsubsection{Sorption Selectivity}

The complexity of industrial effluents, which are characterized by the presence of numerous metal ions, makes it necessary to evaluate the impact of the presence of other base metals on the recovery of REEs. In order to evaluate the selectivity of the sorbent for REEs, the sorption of target metals from multi-component solutions was investigated at different $\mathrm{pH}$ values (Figure 8). The selectivity coefficient is defined as the ratio of distribution coefficients, $\mathrm{D}_{\mathrm{REE}} / \mathrm{D}_{\text {metal }}$ :

$$
\mathrm{SC}_{\mathrm{Pr} / \text { metal }}=\frac{\mathrm{D}_{\mathrm{Pr}}}{\mathrm{D}_{\text {metal }}}=\frac{q_{\mathrm{eq}}^{\mathrm{Pr}} / C_{\mathrm{eq}}^{\mathrm{Pr}}}{q_{\mathrm{eq}}^{\text {metal }} / \mathrm{C}_{\mathrm{eq}}^{\text {metal }}}
$$
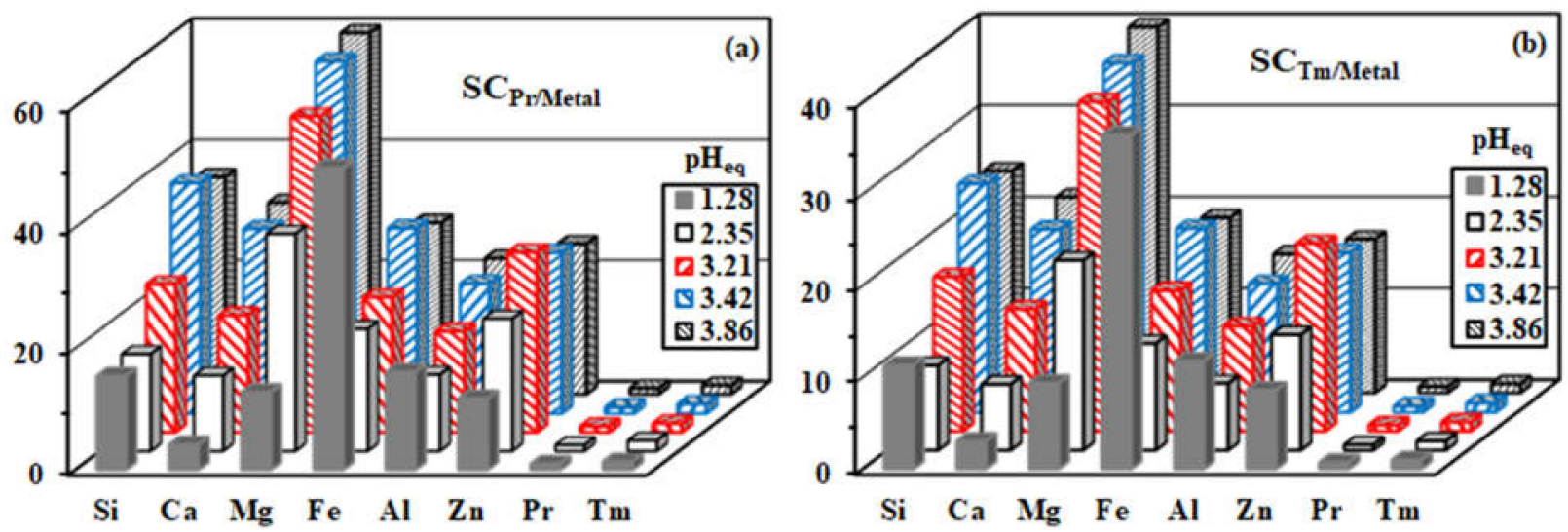

Figure 8. Effect of $\mathrm{pH}_{\mathrm{eq}}$ on the selectivity coefficients of P2-APEI for $\operatorname{Pr}(\mathrm{III})$ (a) and $\mathrm{Tm}(\mathrm{III})$ (b) against other base metals and alkali-earth metals (equimolar $1 \mathrm{mM}$ solutions; SD: $0.5 \mathrm{~g} \mathrm{~L}^{-1}$; contact time: $48 \mathrm{~h}$; $\mathrm{T}: 22 \pm 1{ }^{\circ} \mathrm{C}$ ).

Figure 8 shows that P2-APEI has a strong selectivity for REEs against base metals (iron, aluminum, zinc), alkali-earth metals (calcium and magnesium), and metalloids (silicon). Consistent with previous studies in mono-component solutions, the sorption properties of $\operatorname{Pr}(\mathrm{III})$ and $\mathrm{Tm}$ (III) were so close that their separation with the sorbent was revealed to be difficult. The sorbent had little preference for $\operatorname{Pr}(\mathrm{III}) \mathrm{vs}$. $\mathrm{Tm}(\mathrm{III})$ : the $\mathrm{SC}_{\mathrm{Pr} / \mathrm{Tm}}$ varied between 1.37 and 1.73 (depending on the $\mathrm{pH}$ ); however, this preference is not sufficient for effectively achieving the separation of LREEs from HREEs.

Except for iron, the lowest selectivity coefficients of P2-APEI for REEs against competitor elements were observed at $\mathrm{pH}$ 1.28: $\mathrm{SC}_{\mathrm{Pr} / \mathrm{Fe}}$ and $\mathrm{SC}_{\mathrm{Tm} / \mathrm{Fe}}$ were close to 50 and 36, respectively. At the other $\mathrm{pH}$ values, the $\mathrm{SC}$ values generally increased with the $\mathrm{pH}$. The sorbent also showed a higher selectivity against other metals for $\operatorname{Pr}(\mathrm{III})$ than for $\mathrm{Tm}$ (III). The best separation of REEs from other elements was reached for $\mathrm{pH}$ superior to 3.2 (except iron).

For $\operatorname{Pr}(\mathrm{III})$, the SC followed the series (SC, $\mathrm{pH}$ ): $\mathrm{Tm}<<\mathrm{Al}[22.5, \mathrm{pH} 3.86]<\mathrm{Zn}[29.7$, $\mathrm{pH}$ 3.21] $<\mathrm{Ca}[31.7, \mathrm{pH} 3.86]<\mathrm{Si}[38.0, \mathrm{pH} 3.42]<<\mathrm{Fe}[49.9, \mathrm{pH} 1.28]<<\mathrm{Mg}[59.8, \mathrm{pH} 3.86]$.

For $\mathrm{Tm}(\mathrm{III})$, the ranking followed: $\mathrm{Pr}<<\mathrm{Al}[15.2, \mathrm{pH} 3.86]<\mathrm{Zn}[20.5, \mathrm{pH} 3.21]<$ $\mathrm{Ca}[21.4, \mathrm{pH} 3.86]<\mathrm{Si}[24.9, \mathrm{pH} 3.42]<<\mathrm{Fe}[36.5, \mathrm{pH} 1.28]<<\mathrm{Mg}[40.3, \mathrm{pH} 3.86]$.

The competition effect may be controlled by several parameters such as the ionic charge of the competitor metal, the ionic radius, and the hard/soft behavior. For trivalent cations, the sorbents had a lower selectivity against $\mathrm{Al}(\mathrm{III})$ than $\mathrm{Fe}(\mathrm{III})$, which are both considered hard acids. However, $\mathrm{Al}(\mathrm{III})$ had a smaller hydrated radius (i.e., $0.535 \AA$ ) than $\mathrm{Fe}(\mathrm{III})$ (i.e., $0.645 \AA$ ). In addition, the Fe(III) solution electronegativity was higher than that of $\mathrm{Al}(\mathrm{III})(\chi=3.835$ vs. 3.435$)$; the softness parameter, $\sigma$, was +0.33 for $\mathrm{Fe}(\mathrm{III})$ vs. -0.31 for $\mathrm{Al}(\mathrm{III})$. In the case of divalent cations, $\mathrm{Zn}$ (II) ranked in the borderline class according to the HSAB theory, contrary to $\mathrm{Mg}(\mathrm{II})$ and $\mathrm{Ca}(\mathrm{II})$, which are hard acids. This ranking is not sufficient for explaining the specific behavior of $\mathrm{Zn}(\mathrm{II})$, for which the selectivity coefficient was comparable to $\mathrm{Ca}$ (II), but was much lower than $\mathrm{Mg}$ (II). $\mathrm{Zn}$ (II) had a hydrated radius 
comparable to $\mathrm{Mg}(\mathrm{II})(0.72 \AA$ vs. $0.74 \AA$ ) and was much lower than $\mathrm{Ca}(\mathrm{II})$ (i.e., $1.12 \AA$ ). $\mathrm{Zn}$ (II) had a positive softness $\sigma$ (i.e., +0.35 ) contrary to $\mathrm{Ca}$ (II) and $\mathrm{Mg}$ (II) (i.e., -0.66 and -0.41 , respectively). The solution electronegativity $\chi$ cannot be correlated to the selectivity order: 2.796 for $\mathrm{Zn}(\mathrm{II}), 2.158$ for $\mathrm{Mg}(\mathrm{II})$, and 1.862 for $\mathrm{Ca}$ (II). The different criteria showed contradictory trends regarding the evolution of the SC coefficient of REEs vs. these competitor cations. Therefore, it appears difficult to correlate the binding of the competitor ions with these physicochemical characteristics.

Figure S10 shows the $\log _{10}$ plot of the distribution ratio of selected metals vs. the equilibrium $\mathrm{pH}$. The quasi-linear curves shifted by one to two orders of magnitude for REEs compared with other competitor elements. In conclusion, despite the difficulty in interpreting the relative effects, at pH 3.2-3.9, P2-APEI showed a clear preference for REEs against other divalent or trivalent cations that are frequently present in the ore leachates.

Table S8 summarizes the semi-quantitative EDX analysis of the surface and crosscut section for the P2-APEI sorbent after contact with multi-metal solutions at different $\mathrm{pH}$ values. The morphology of the material was not changed by the $\mathrm{pH}$ at both the surface and in the crosscut section. The semi-quantitative analysis confirmed the trends observed in the mass balance of individual metals during the sorption step (and the effect of $\mathrm{pH}$ in metal recovery). The concentrations of the REEs were of the same order of magnitude at the surface and in the inner part of the sorbent. This result confirms the readily accessibility of internal reactive groups for target metals.

\subsubsection{Metal Desorption and Sorbent Recycling}

Previous studies have shown the efficiency of acid solutions for the desorption of metal ions from functionalized APEI beads. The stability of the material can be improved by introducing calcium chloride (for the stabilization of alginate matric). The metal-loaded sorbents collected at the end of the sorption process were tested for metal desorption using $0.2 \mathrm{M} \mathrm{HCl} / 0.5 \mathrm{M} \mathrm{CaCl}_{2}$ solutions for the study of the desorption kinetics (Figure 9 for mono-metal samples, Figure S11 for bi-metal samples). These curves clearly show that the desorption of both $\operatorname{Pr}(\mathrm{III})$ and $\mathrm{Tm}(\mathrm{III})$ was highly efficient for both APEI and P2-APEI: metal desorption systematically exceeded $99 \%$ and the time required for achieving these elution rates did not exceed 25-30 min. For mono-metal loaded resins, the desorption profiles were overlapped for the APEI sorbent, while for P2-APEI $\operatorname{Pr}(\mathrm{III})$, desorption was apparently faster than for $\mathrm{Tm}(\mathrm{III})$. In the case of sorbents loaded with binary solutions, the desorption profiles were also a little faster for $\operatorname{Pr}(\mathrm{III})$ compared with $\mathrm{Tm}(\mathrm{III})$. The PFORE and the PSORE equations were applied to fit the kinetic profiles [76].
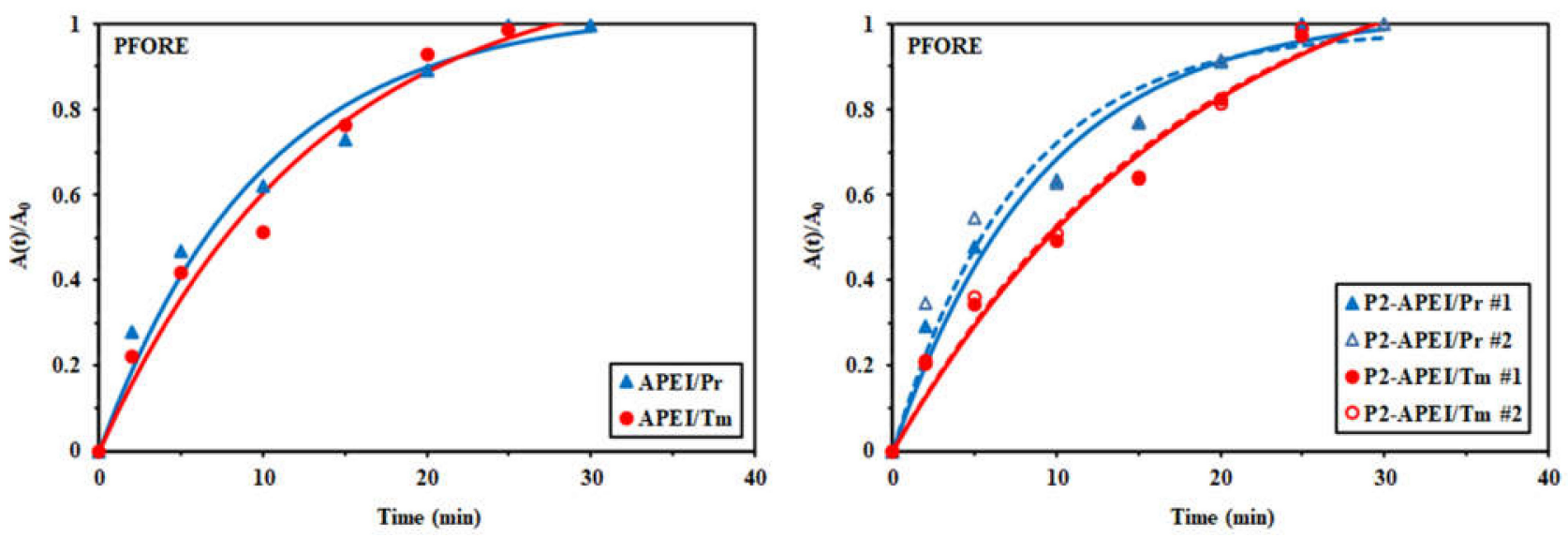

Figure 9. $\operatorname{Pr}(\mathrm{III})$ and $\mathrm{Tm}(\mathrm{III})$ desorption kinetics for APEI and P2-APEI-modeling with the PFORE (loaded sorbents collected from uptake kinetics; desorption using $0.2 \mathrm{M} \mathrm{HCl} / 0.5 \mathrm{M} \mathrm{CaCl}_{2} ; \mathrm{SD}: 1 \mathrm{~g} \mathrm{~L}^{-1}, \mathrm{~T}: 22 \pm 1{ }^{\circ} \mathrm{C} ; \mathrm{A}(\mathrm{t}) / \mathrm{A}_{0}$ : metal amount desorbed referred to initial sorbed amount). 
Tables 6 and 7 report the parameters of these models for $\operatorname{Pr}(\mathrm{III})$ and $\mathrm{Tm}$ (III) desorption from APEI and P2-APEI loaded with mono-metal solutions; the data for bi-metal loaded sorbents are reported in Table S9. In most cases, the PSORE better fit the experimental profiles (especially for $\operatorname{Pr}(\mathrm{III})$ sorption), contrary to the sorption step that was preferentially described by the PFORE, probably due to the contribution of a ligand exchange mechanism. However, it is noteworthy that the PFORE allows for better approaching the effective sorption capacity, which is significantly overestimated by the PSORE, especially for Tm(III) recovery. The comparison of the orders of magnitude of the rate coefficients for desorption, both $\mathrm{k}_{\mathrm{d} 1}$ and $\mathrm{k}_{\mathrm{d} 2}$, with the relevant values for the sorption step showed relatively faster desorption. On the other hand, the comparison of rate coefficients for binary solutions with mono-component solutions showed that desorption was faster for binary systems in the case of APEI sorbent, in contrast to P2-APEI (where the rate coefficients were higher for mono-component solutions).

Table 6. Pr(III) desorption kinetics using APEI and P2-APEI sorbents-fitting parameters for the PFORE and PSORE models.

\begin{tabular}{ccccc}
\hline & & & \multicolumn{2}{c}{ Sorbent } \\
\cline { 3 - 4 } Model & Parameter & APEI & P2-APEI & 2nd Run \\
\cline { 3 - 5 } & & & 0.356 & 0.347 \\
Exp. & $q_{\text {eq,exp }}\left(\mathrm{mmol} \mathrm{g}^{-1}\right)$ & 0.0788 & 0.343 \\
& $q_{1, \text { calc }}\left(\mathrm{mmol} \mathrm{g}^{-1}\right)$ & 0.0813 & 0.365 & 1.32 \\
PSORE & $k_{1} \times 10\left(\mathrm{~min}^{-1}\right)$ & 1.02 & 1.10 & 0.962 \\
& $\mathrm{R}^{2}$ & 0.980 & 0.983 & -53 \\
& $\mathrm{AIC}_{2, \mathrm{calc}}\left(\mathrm{mmol} \mathrm{g}^{-1}\right)$ & -82 & -59 & 0.419 \\
& $k_{2} \times 10\left(\mathrm{~L} \mathrm{~mol}^{-1} \mathrm{~min}^{-1}\right)$ & 0.105 & 0.466 & 3.51 \\
$\mathrm{R}^{2}$ & 9.45 & 2.34 & 0.990 & -576 \\
\hline
\end{tabular}

Table 7. Tm(III) desorption kinetics using the APEI and P2-APEI sorbents-fitting parameters for the PFORE and PSORE models.

\begin{tabular}{|c|c|c|c|c|}
\hline \multirow{3}{*}{ Model } & \multirow{3}{*}{ Parameter } & \multicolumn{3}{|c|}{ Sorbent } \\
\hline & & \multirow{2}{*}{ APEI } & \multicolumn{2}{|c|}{ P2-APEI } \\
\hline & & & 1st Run & 2nd Run \\
\hline Exp. & $q_{\text {eq,exp }}\left(\mathrm{mmol} \mathrm{g}^{-1}\right)$ & 0.0609 & 0.271 & 0.270 \\
\hline \multirow[t]{4}{*}{ PFORE } & $q_{1, \text { calc }}\left(\mathrm{mmol} \mathrm{g}^{-1}\right)$ & 0.0693 & 0.343 & 0.336 \\
\hline & $k_{1} \times 10\left(\min ^{-1}\right)$ & 0.756 & 0.531 & 0.553 \\
\hline & $\mathrm{R}^{2}$ & 0.983 & 0.987 & 0.985 \\
\hline & AIC & -87 & -65 & -64 \\
\hline \multirow[t]{4}{*}{ PSORE } & $q_{2, \text { calc }}\left(\mathrm{mmol} \mathrm{g}^{-1}\right)$ & 0.0964 & 0.506 & 0.489 \\
\hline & $\begin{array}{c}k_{2} \times 10^{1}\left(\mathrm{~L} \mathrm{mmol}^{-1}\right. \\
\left.\min ^{-1}\right)\end{array}$ & 6.45 & 0.777 & 0.855 \\
\hline & $\mathrm{R}^{2}$ & 0.984 & 0.987 & 0.986 \\
\hline & AIC & -88 & -66 & -65 \\
\hline
\end{tabular}

The PFORE and PSORE models were applied for desorption (according to Daneshvar et al., [76])

$$
\begin{gathered}
\text { PFORE - Desorption : } q_{d}=q_{d, 1}\left(1-e^{-k_{d, 1} \times t}\right) \\
\text { PSORE - Desorption : } q_{d}=\frac{q_{d, 2}^{2} \times k_{d, 2} \times t}{1+\left(k_{d, 2} \times q_{d, 2} \times t\right)}
\end{gathered}
$$


In a second step, the recycling of the functionalized sorbent was investigated using a $0.2 \mathrm{M} \mathrm{HCl} / 0.5 \mathrm{M} \mathrm{CaCl}_{2}$ solution (operating a washing step between each sorption and desorption steps). The comparison of sorption and desorption efficiencies is summarized in Table 8. Sorption efficiency progressively decreased with recycling. However, at the fifth cycle, the loss was close to $10 \%$ for both $\operatorname{Pr}(\mathrm{III})$ and $\mathrm{Tm}(\mathrm{III})$. On the other hand, the elution of target metals was complete and remarkably stable for the five cycles. Figure 2 shows that the FTIR spectrum of P2-APEI submitted to fives cycles of sorption and desorption hardly changed. This may explain the relative stability in the sorption performances. On the other hand, the comparison of Tables S2c and S7c showed that the concentrations of $\mathrm{Ca}$ and $\mathrm{Cl}$ at the surface and in the crosscut section of the functionalized sorbent increased after elution due to ion-exchange mechanisms associated with the composition of the eluent (i.e., $\mathrm{HCl}$ and $\mathrm{CaCl}_{2}$ solutions).

Table 8. Sorption and desorption performances (efficiencies, \%) for five successive cycles for $\operatorname{Pr}(\mathrm{III})$ and $\mathrm{Tm}(\mathrm{III})$ recovery using the P2-APEI sorbent.

\begin{tabular}{cccccc}
\hline \multirow{2}{*}{ Metal Ion } & & \multicolumn{2}{c}{ Sorption } & \multicolumn{2}{c}{ Desorption } \\
& Cycle & $\begin{array}{c}\text { SE } \\
\mathbf{( \% )}\end{array}$ & $\begin{array}{c}\text { St. Dev. } \\
\mathbf{( \% )}\end{array}$ & $\begin{array}{c}\text { DE } \\
\mathbf{( \% )}\end{array}$ & $\begin{array}{c}\text { St. Dev. } \\
\mathbf{( \% )}\end{array}$ \\
\hline \multirow{3}{*}{$\operatorname{Pr}(\mathrm{III})$} & \#1 & 99.1 & 0.3 & 100.0 & 0.3 \\
& $\# 2$ & 97.7 & 0.6 & 100.5 & 0.5 \\
& $\# 3$ & 96.5 & 0.6 & 100.1 & 0.1 \\
& $\# 4$ & 94.2 & 0.1 & 100.1 & 0.0 \\
& $\# 5$ & 91.0 & 1.5 & 100.0 & 0.2 \\
\hline \multirow{3}{*}{$\operatorname{Tm}(\mathrm{III})$} & $\# 1$ & 91.9 & 0.6 & 99.9 & 0.1 \\
& $\# 2$ & 89.6 & 0.6 & 100.5 & 0.5 \\
& $\# 3$ & 87.2 & 0.5 & 100.2 & 0.6 \\
& $\# 4$ & 84.5 & 0.9 & 100.4 & 0.1 \\
& $\# 5$ & 82.7 & 0.6 & 99.7 & 0.2 \\
\hline
\end{tabular}

\subsection{Application to Metal Recovery from Acid Leaching of Tailing Material}

\subsubsection{Pre-Treatment of Leachates}

The compositions of the ore and tailing are compared in Table S10. Although the conventional acid leaching recovered $\sim 50 \%$ to $90 \%$ of valuable metals, the characterization of tailings clearly demonstrates that some strategic metals (such as $\mathrm{U}, \mathrm{Cu}$, and REEs) are still present in the mining residues at relatively high concentrations. Table S11 reports the composition of the leachates produced after pug leaching of ore tailings. Based on the huge concentrations of iron and aluminum, pre-treatments steps were operated to first remove iron with a precipitation step of the leachate at $\mathrm{pH} 4$, followed by the precipitation of aluminum at $\mathrm{pH}$ 5. The results summarized in Table S11 confirm the progressive reduction of iron and aluminum (abatement reached while the concentrations of the other elements were marginally affected by the pre-treatments (the loss was less than $8 \%$ for $\mathrm{Si}, 4 \%$ for $\mathrm{Ca}$, $8 \%$ for $\mathrm{Mn}, 10 \%$ for $\mathrm{Ni}, 4 \%$ for $\mathrm{Cu}$, and $16 \%$ for $\mathrm{Zn}$ ). In the case of REEs, the losses were close to $3.6 \%$ for $\mathrm{Pr}, 6.1 \%$ for $\mathrm{Nd}$, and $7.4 \%$ for $\mathrm{Tm}$; this was confirmed by the $2.7 \%$ total loss of REEs while using the global REE index. The precipitation steps were relatively selective and did not induce substantial loss of strategic elements. The major elements present in the pre-treated solutions were $\mathrm{Ca}(\mathrm{II})$ (i.e., $1833 \mathrm{mg} \mathrm{Ca} \mathrm{L}^{-1}$ ) and $\mathrm{Cu}(\mathrm{II})$ (i.e., $~ 183 \mathrm{mg} \mathrm{Cu} \mathrm{L}^{-1}$ ); other elements were systematically lower than $100 \mathrm{mg} \mathrm{L}^{-1}$. The global REE index was close to $94.9 \mathrm{mg} \mathrm{L}^{-1}$. This level of concentration is consistent with the range of concentrations where sorption processes may be used.

\subsubsection{Metal Recovery from Pre-Treated Solutions}

The sorption process was applied to pre-treated leachates at different $\mathrm{pH}_{\mathrm{eq}}$ values (ranging between 1.38 and 3.91). The residual concentrations are also summarized in Table S11. It appears that the sorption process poorly affects the residual concentrations of 
the base metals (and metalloid): the concentrations decreased by less than $13 \%$ even in the most favorable $\mathrm{pH}$ conditions, with the remarkable exception of the $\mathrm{Zn}$ (II) concentration, which decreased by $25.3 \%$ at $\mathrm{pH}_{\mathrm{eq}}$ 3.91. On the other hand, the pre-treated leachate was almost exhausted in terms of REEs: the recoveries reached $94 \%$ for $\mathrm{Nd}(\mathrm{III}), 93.5 \%$ for $\operatorname{Pr}(\mathrm{III})$, and almost $93.1 \%$ for Tm(III) $\left(84.3 \%\right.$ in terms of global REE index) at the highest $\mathrm{pH}\left(\mathrm{pH}_{0}: 5\right.$, $\mathrm{pH}_{\mathrm{eq}}$ : 3.91). The distribution ratios (D) increased with the $\mathrm{pH}$ for the different metals (Table S12); however, this enhancement was especially important for REEs and the D values were remarkably higher at $\mathrm{pH}_{\mathrm{eq}} 3.91$ (values in the range $1.36-1.56 \times 10^{4} \mathrm{~L} \mathrm{~g}^{-1}$ ). These results clearly demonstrate that, despite the complexity of the solutions, the sorbent had a high affinity for REEs, with a high effect of concentration and limited impact of competitor metal ions. Table S13 shows the micrographs of surface and crosscut sections of P2-APEI after being in contact with the pre-treated leachates at different $\mathrm{pH}$ values. The sorption process and the $\mathrm{pH}$ did not significantly affect the morphology of the material. Table S14 reports the semi-quantitative analysis of the sorbent exposed to the pre-treated leachate at $\mathrm{pH}_{0} 5$. The complete family of REEs (with the remarkable exception of Sc) was detected both at the surface and in the internal compartment of the sorbent. It is noteworthy that Sc was not identified in the series of REEs and associated elements (such as Y).

\subsubsection{Rare Earth Elements (REEs) Separation and Precipitation as Oxalate Salts}

After the sorption step, metal-loaded P2-APEI was eluted with $0.2 \mathrm{M} \mathrm{HCl} / 0.5 \mathrm{M}$ $\mathrm{CaCl}_{2}$. Table $\mathrm{S} 15$ reports the concentration of metal ions in the eluate from the sorbents loaded at different $\mathrm{pH}$ values. For base metals (and metalloid, $\mathrm{Si}(\mathrm{IV})$ ), the concentrations on the sorbent were very low, but the desorption was very efficient: desorption efficiencies were systematically higher than $94 \%$ (not shown) for optimized sorption $\mathrm{pH}$ (i.e., $\mathrm{pH}_{0} 5$ and $\mathrm{pH}_{\mathrm{eq}}$ 3.91). In the case of REEs, despite higher amounts of sorbed metals, the elution yields were maintained higher than $96 \%$ (for Tm) and up to $99 \%$ (for $\mathrm{Nd}$ ). Oxalic acid (at controlled $\mathrm{pH}$ ) is a very efficient and selective precipitating agent for the recovery of rare earth elements [11,77-79]. The treatment of eluates with oxalic acid solution $(15 \%, w / w)$ at $\mathrm{pH} 1$ allows for quantitatively recovering REEs: the precipitation efficiency ranged between $98 \%$ and $98.5 \%$ (not shown). Table S16 summarizes the concentrations of selected metals in the residue (filtrate) of the oxalic acid precipitation step. It is noteworthy that the oxalic acid precipitation method requires a sufficient amount of REEs to be present for efficient precipitation; this is not the case with the sorbents loaded at low $\mathrm{pH}$ and this can explain the relative high residual $\mathrm{REE}$ concentration when the sorbent was loaded at $\mathrm{pH}_{\mathrm{eq}}$ equal or lower than 3.91. The weak residual concentrations of the REEs after oxalic acid precipitation for the eluates produced in the desorption of the sorbent loaded at the highest $\mathrm{pH}$ values, confirmed the strong efficiency of this treatment for the selective recovery of REEs from eluates. The combination of this treatment with the appropriate selection of the $\mathrm{pH}$ of sorption (at $\mathrm{pH}_{0} 4-5$ ), and the desorption using the $\mathrm{CaCl}_{2} / \mathrm{HCl}$ eluate allows for highly efficient recovery and separation of REEs from complex solutions. On the other hand, the base metals (and Si) eluted from the sorbent were poorly precipitated (in the range 3-20\%). Therefore, the precipitate of REEs oxalate was supposed to be relatively pure. Table S17 shows the semi-quantitative EDX analysis of the oxalate precipitate collected from the eluate of the sorbent loaded at $\mathrm{pH}_{0} 5\left(\mathrm{pH}_{\mathrm{eq}}\right.$ 3.91). Carbon and oxygen are associated with the oxalate ligand, and the presence of nitrogen and calcium mark the only significant impurities present in the precipitate. The use of the concentrated acidic solution of calcium chloride for the elution of the sorbent may explain the presence of $\mathrm{Ca}$ (at weight/atomic concentrations close to 1\%). Usually, the REE oxalate precipitates are finally submitted to a calcination process for producing pure REE oxides [79]. Figure S12 compares the distribution of REEs in the sorbent and the oxalate precipitate (based on semi-empirical EDX analyses) to verify that the elution/precipitation process can contribute to enrich and separate the REEs. The enrichment factor (EF), defined here as the ratio of the percentage of the REE in the oxalate precipitate to its fraction onto the sorbent, did not follow any 
clear trend (atomic number, ionic radius, etc.). There was no correlation between their enrichment factor and belonging to LREEs or HREEs.

EF ranking: $\mathrm{La}(\mathrm{EF}: 0.14)<\mathrm{Lu}<\mathrm{Er}<\mathrm{Ho}<\mathrm{Ce}<\mathrm{Pm}<\mathrm{Yb}<\mathrm{Tb}<\mathrm{Tm}<\mathrm{Tm}<\mathrm{Dy}(\mathrm{EF}: 0.93)$ $<\operatorname{Pr}(\mathrm{EF}: 1.24)<\mathrm{Gd}<\mathrm{Y}<\mathrm{Sm}<\mathrm{Nd}<\mathrm{Eu}(\mathrm{EF}: 7.8)$.

The mass balance on the distribution of selected elements in the different compartments of the sequential treatments is presented for the different $\mathrm{pHs}$ in Figure $10 \mathrm{pH}_{0} 5$ and $\mathrm{pH}_{\mathrm{eq}}$ 3.91, the optimum condition for REE separation from other base metals and metalloid) and Figure S13 (for other $\mathrm{pH}$ values). Consistently with their specific treatments, $\mathrm{Fe}$ and $\mathrm{Al}$ were recovered $(>90 \%)$ in the precipitates collected at $\mathrm{pH} 4$ and $\mathrm{pH} 5$, respectively. For $\mathrm{Si}, \mathrm{Ca}, \mathrm{Mn}, \mathrm{Ni}, \mathrm{Cu}$, and $\mathrm{Zn}$, most of the metal ions were recovered in the solutions issued from the sorption step (poorly sorbed): around $80-90 \%$ (only $63.4 \%$ in the case of $\mathrm{Zn})$.

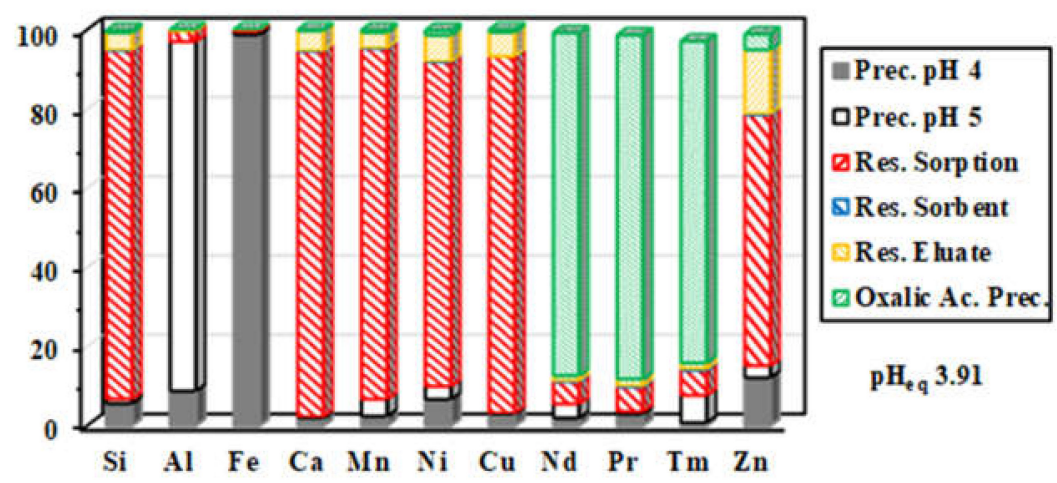

Figure 10. Distribution of the selected metals in the different compartments of the global treatment process ( $\mathrm{pH} 4$ precipitate $(\mathrm{Fe}) ; \mathrm{pH} 5$ precipitate $(\mathrm{Al})$; residual solution after sorption at $\mathrm{pH}_{0} 5$ (Res. Sorption); metal residue on the sorbent after elution (Res. Sorbent), residue in the eluate and oxalic acid precipitate).

Low amounts of these elements were found in the residue of eluate precipitation $(0-6.7 \%, 16.2 \%$ in the specific case of $\mathrm{Zn})$. The rare earth elements were essentially collected in the oxalate precipitate: $86.9 \%$ for $\mathrm{Pr}, 86.6 \%$ for $\mathrm{Nd}$, and $81.3 \%$ for $\mathrm{Tm}$. The precipitation pre-treatments lost 3.5\% (for Pr) to 7.6\% (for Tm), the amounts of REEs not bound (released in the residue of sorption step) represented $5.7 \%$ to $6.3 \%$, while the amounts tightly bound to the sorbent (not eluted) did not exceed $0.33 \%$. The strong efficiency of oxalic precipitation for REE precipitation allows limiting their loss below $1.8 \%$. For comparison, this distribution of metals in the different compartments for the other $\mathrm{pH}$ values (used for sorption step) is also reported in Figure S13: the other $\mathrm{pH}$ values induced less selective separation of the different metals.

\section{Conclusions}

A new member in the family of derivatives of alginate/algal biomass/PEI composites (APEI beads) was successfully synthesized by phosphorylation of the raw material. This functionalization was performed in two steps including the activation of the material with epichlorohydrin, followed by a reaction with triethyl phosphite. The combination of different analytical tools allowed for characterizing the physical (BET, TGA, SEM) and chemical (EDX, FTIR, XPS, titration) properties of the different materials. Successful functionalization was demonstrated, but these techniques also confirmed the contribution of different reactive groups (carboxylic, hydroxyl, amine, P-based groups) on the binding of a light REE (i.e., $\operatorname{Pr}(\mathrm{III})$ ) and a heavy REE (i.e., $\mathrm{Tm}(\mathrm{III})$ ) as free $\mathrm{REE}^{3+}$ or as a sulfate complex. The functionalization of APEI beads increased sorption performance by a factor close to 3 . The sorption efficiency increased with the $\mathrm{pH}$ : optimum initial $\mathrm{pH}$ was found to be close to 5 (while the equilibrium $\mathrm{pH}$ tends to $\mathrm{pH} 4.3$ ). The structure of the beads (macroporous scaffold) with a specific surface area close to $40 \mathrm{~m}^{2} \mathrm{~g}^{-1}$ may explain that the 
resistance to intraparticle diffusion is negligible in the control of uptake kinetics, which are efficiently fitted by the pseudo-first order rate equation. Forty to $60 \mathrm{~min}$ was sufficient to reach equilibrium. The desorption of the REEs was also very efficient (higher than $98 \%$ ) and fast (30-40 $\mathrm{min}$ ) using $0.2 \mathrm{M} \mathrm{HCl} / 0.5 \mathrm{M} \mathrm{CaCl}_{2}$ solutions. The sorption and desorption performances were remarkably stable over five cycles: the loss in sorption efficiency was less than $10 \%$ at the fifth cycle, while the metal remained completely eluted even at the last cycle. Sorption isotherms were successfully modeled using the Langmuir equation and the maximum sorption capacities at the saturation of the monolayer were close to $2.14 \mathrm{mmol} \mathrm{Pr} \mathrm{g}^{-1}$ and $1.57 \mathrm{mmol} \mathrm{Tm} \mathrm{g}^{-1}$. These values were globally higher than those reported in the literature. Sorption tests performed in multi-metal solutions clearly demonstrate that the new sorbent had a marked preference for REEs against base metals or alkali-earth metals, especially at $\mathrm{pH}_{\mathrm{eq}} 3.42-3.86$. Although the selectivity was not high enough for separating $\operatorname{Tm}(\mathrm{III})$ from $\operatorname{Pr}(\mathrm{III})$, the sorbent had a preference for the lighter of the two REEs.

A process was designed for the valorization of tailing residues. The mining waste was the first pug leached to recover multi-metal solutions containing high concentrations of aluminum and iron, which are successively precipitated at $\mathrm{pH} 4$ and $\mathrm{pH} 5$ (with limited loss of other metal ions). In a second part of the process, the leachates were successfully treated by sorption for the recovery of REEs with relatively good separation from base metals, alkali earth elements, and Si(IV) by sorption on the phosphorylated sorbent. The desorption of the sorbent produced an eluate that contained most REEs and traces of zinc. The precipitation of the eluate with oxalic acid at $\mathrm{pH} 1$ allows for selectively recovering REE-oxalate with good purity.

Supplementary Materials: The following are available online at https:/ /www.mdpi.com/2075-470 1/11/2/294/s1, Figure S1: title, Table S1: title, Video S1: title. Table S1a. Modeling of uptake kinetics, Table S1b. Modeling of sorption isotherms, Table S2a. SEM-EDX of raw beads (APEI)/surface and crosscut section, Table S2b. SEM-EDX analysis of activated chloride beads (spacer arm)/surface and crosscut section, Table S2c. SEM-EDX of sorbent after grafting of phosphoryl groups, Table S3. FTIR assignments and wavenumber $\left(\mathrm{cm}^{-1}\right)$ of APEI, APEI-Cl, and P2-APEI beads, Table S4. FTIR assignments and wavenumber $\left(\mathrm{cm}^{-1}\right)$ of P2-APEI, loaded sorbent with either $\operatorname{Pr}(\mathrm{III})$ and Tm(III), and after five cycles of sorption and desorption, Table S5a. C 1s signal for APEI and P2-APEI (before and after metal sorption), Table S5b. O 1s signal for APEI and P2-APEI (before and after metal sorption), Table S5c. N 1s signal for APEI and P2-APEI (before and after metal sorption), Table S5d. P 2p signal for APEI and P2-APEI (before and after metal sorption), Table S5e. XPS signals, assignments, and atomic fraction (AF into parenthesis) for APEI and P2-APEI (before and after metal sorption), Table S6. Elemental analysis of APEI and P2-APEI sorbents, Table S7a. SEM-EDX of raw beads (APEI) before and after loading with $\operatorname{Pr}(\mathrm{III})$ and $\mathrm{Tm}(\mathrm{III})$ (surface and crosscut section) at $\mathrm{pH}_{0} 5$, Table S7b. SEM-EDX of loaded P2-APEI sorbent (surface and crosscut section), Table S7c. SEM-EDX of P2APEI sorbent after elution (surface and crosscut section), Table S8. SEM-EDX analysis of P2-APEI after being treated with an equimolar solution at different $\mathrm{pH}$ values, Table S9. $\operatorname{Pr}(\mathrm{III})$ and $\mathrm{Tm}$ (III) desorption kinetics using APEI and P2-APEI sorbents from binary solutions-fitting parameters for the PFORE and PSORE models, Table S10. Composition of ore and tailing-main elements, Table S11. Composition of tailing leachate and after successive pre-treatments, Table S12. Distribution ratio $\left(\mathrm{D}, \mathrm{L} \mathrm{g}^{-1}\right)$ for the sorption of metals from pre-treated leachates (at different values of $\mathrm{pH}_{\mathrm{eq}}$ ), Table S13. SEM analysis of P2-APEI beads (surface and crosscut section) after the sorption step onto the pre-treated leachate of tailings, Table S14. EDX analysis of the sorbent (surface and crosscut section) after application at $\mathrm{pH}_{0} 5$, Table S15. Metal concentrations $\left(\mathrm{mg} \mathrm{L}^{-1}\right)$ in the eluate from sorbent loaded at different values of $\mathrm{pH}_{\mathrm{eq}}$, Table $\mathrm{S16}$. Metal concentrations $\left(\mathrm{mg} \mathrm{L}^{-1}\right)$ in the residue of oxalic acid precipitation from eluates collected from the sorbent loaded at different values of $\mathrm{pH}_{\mathrm{eq}}$, Table S17. EDX analysis of the oxalate precipitate from the sorbent loaded at $\mathrm{pH}_{0} 5$. Figure $\mathrm{S} 1$. Textural analysis of APEI and P2-APEI sorbents-(a) $\mathrm{S}_{\mathrm{BET}}$ surface area, (b) pore size distribution, Figure S2. Thermogravimetric analysis of the APEI and P2-APEI sorbents, Figure S3. FTIR spectra of APEI, activated APEI (chloromethylated APEI, APEI-Cl), and phosphorylated APEI (P2-APEI) beads (focus on selected wavenumber ranges), Figure S4. FTIR spectra of sorbents (before and after metal sorption, and after regeneration) (focus on specific wavenumber ranges), Figure S5. 
Determination of $\mathrm{pH}_{\mathrm{PZC}}$ for APEI and P2-APEI sorbents, Figure S6. Pr(III) and Tm(III) speciation diagrams (experimental conditions used for the study of $\mathrm{pH}$ effect), Figure $\mathrm{S7}$. $\mathrm{pH}$ variation during $\operatorname{Pr}(\mathrm{III})$ and Tm(III) sorption using APEI (a) and P2-APEI (b) sorbents, Figure S8a. Pr(III) and Tm(III) uptake kinetics using APEI and P2-APEI sorbents (duplicate experiments), Figure S8b. $\operatorname{Pr}(\mathrm{III})$ and Tm(III) uptake kinetics using APEI and P2-APEI sorbents from binary solutions, Figure S9. $\operatorname{Pr}(\mathrm{III})$ and Tm(III) sorption isotherms using APEI and P2(APEI (duplicate experiments), Figure S10. Effect of $\mathrm{pH}_{\mathrm{eq}}$ on the distribution ratio of selected metals ( $\log _{10}$ D plots), Figure S11. Pr(III) and Tm(III) desorption kinetics for APEI and P2-APEI from the binary solution-modeling with the PFORE, Figure S12. Relative percentages of the different REEs in the sorbent (cross-section) at $\mathrm{pH}_{0}: 5,(\mathrm{a})$ ) and in the oxalic acid precipitate (b) (semi-quantitative EDX analysis), Figure S13. Distribution of selected metals in the different compartments of the global treatment process ( $\mathrm{pH} 4$ precipitate (Fe); $\mathrm{pH} 5$ precipitate (Al); residual solution after sorption at different $\mathrm{pH}_{0}$ values (Res. Sorption); metal residue on the sorbent after elution (Res. Sorbent), Residue in the eluate and the oxalic acid precipitate), Scheme S1. Proposed flow sheet for the treatment of ore residue.

Author Contributions: Methodology, experiment design and investigation: Y.W., E.G., H.M., and M.F.H.; Validation, characterization of sorbents and experiments: C.H., K.A.M.S., M.F.H., and K.Z.E.; Formal analysis, data curation, and visualization: K.A.M.S., H.M., A.A.-H.A.-R., and K.Z.E., software: C.H.; Data analysis, writing and editing: Y.W. and M.F.H.; Analyzed the data, writing, and editing; supervision: Y.W., M.F.H., and Y.W.; Funding acquisition: Y.W. All authors have read and agreed to the published version of the manuscript.

Funding: Y.W. thanks the support of the National Natural Science Foundation of China (NSFC) Projects (No. 11975082, U1967218); the Science and Technology Major Project of Guangxi Province (China) (AA17204100, AA18118030). E.G., M.F.H., A.A.-H.A.-R., and H.M. acknowledge the Institut Francais d'Egypte and Egyptian Academy of Science and Technology, Egypt for supporting the collaboration between IMT-Mines Ales and Nuclear Materials Authority through IMHOTEP project "MetalValor" (ref. 39529QA).

Data Availability Statement: The data presented in this study are available on request from the corresponding authors.

Conflicts of Interest: The authors declare no conflict of interest.

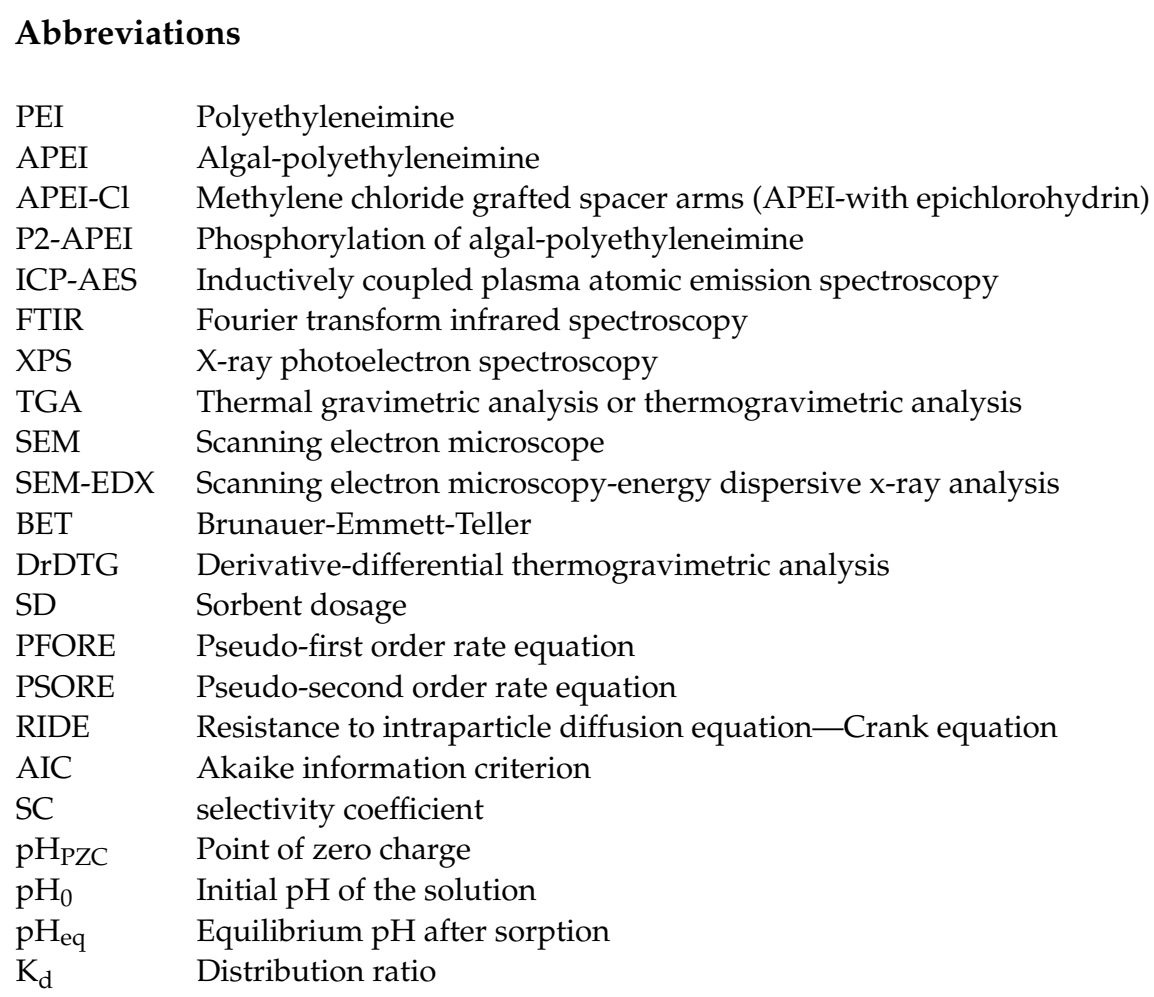




$\begin{array}{ll}\mathrm{C}_{0} & \text { Initial concentration } \\ \mathrm{C}_{\text {eq }} & \text { Equilibrium concentration after metal sorption } \\ \mathrm{BEs} & \text { Binding energies } \\ \mathrm{AF} & \text { Atomic fractions } \\ \mathrm{REEs} & \text { Rare earth elements } \\ \mathrm{HSAB} & \text { Hard and Soft Acid-Base theory } \\ \text { Biopolymer-LDH } & \text { Biopolymer-layered double hydroxides composite }\end{array}$

\section{References}

1. Zhou, B.; Li, Z.; Chen, C. Global Potential of Rare Earth Resources and Rare Earth Demand from Clean Technologies. Minerals 2017, 7, 203. [CrossRef]

2. Wall, F. Rare earth elements. In Critical Metals Handbook; Wiley: Hoboken, NJ, USA, 2014; pp. 312-339.

3. Duarte, F.J. Tunable Lasers Handbook; Elsevier Academic Press: San Diego, CA, USA, 1995; 477p.

4. Haxel, G.B.; Hedrick, J.B.; Orris, G.J.; Stauffer, P.H.; Hendley, J.W. Rare Earth Elements: Critical Resources for High Technology; Fact Sheet 087-02; U.S. Geological Survey: Reston, VA, USA, 2002. [CrossRef]

5. RSC. Periodic Table. Available online: https://www.rsc.org/periodic-table/ (accessed on 30 October 2020).

6. Swain, N.; Mishra, S. A review on the recovery and separation of rare earths and transition metals from secondary resources. $J$. Clean. Prod. 2019, 220, 884-898. [CrossRef]

7. Xu, D.; Shah, Z.; Cui, Y.; Jin, L.; Peng, X.; Zhang, H.; Sun, G. Recovery of rare earths from nitric acid leach solutions of phosphate ores using solvent extraction with a new amide extractant (TODGA). Hydrometallurgy 2018, 180, 132-138. [CrossRef]

8. Yuan, H.; Hong, W.; Zhou, Y.; Pu, B.; Gong, A.; Xu, T.; Yang, Q.; Li, F.; Qiu, L.; Zhang, W.; et al. Extraction and back-extraction behaviors of 14 rare earth elements from sulfuric acid medium by TODGA. J. Rare Earths 2018, 36, 642-647. [CrossRef]

9. Jia, Q.; Wang, Z.H.; Li, D.Q.; Niu, C.J. Adsorption of heavy rare earth(III) with extraction resin containing bis(2,4,4-trimethylpentyl) monothiophosphinic acid. J. Alloys Compd. 2004, 374, 434-437. [CrossRef]

10. Xiong, C.; Zhu, J.; Shen, C.; Chen, Q. Adsorption and Desorption of Praseodymium (III) from Aqueous Solution Using D72 Resin. Chin. J. Chem. Eng. 2012, 20, 823-830. [CrossRef]

11. Yamada, E.; Murakami, H.; Nishihama, S.; Yoshizuka, K. Separation process of dysprosium and neodymium from waste neodymium magnet. Sep. Purif. Technol. 2018, 192, 62-68. [CrossRef]

12. Omodara, L.; Pitkäaho, S.; Turpeinen, E.-M.; Saavalainen, P.; Oravisjärvi, K.; Keiski, R.L. Recycling and substitution of light rare earth elements, cerium, lanthanum, neodymium, and praseodymium from end-of-life applications-A review. J. Clean. Prod. 2019, 236, 117573. [CrossRef]

13. Van der Hoogerstraete, T.; Binnemans, K. Highly efficient separation of rare earths from nickel and cobalt by solvent extraction with the ionic liquid trihexyl(tetradecyl)phosphonium nitrate: A process relevant to the recycling of rare earths from permanent magnets and nickel metal hydride batteries. Green Chem. 2014, 16, 1594-1606. [CrossRef]

14. Zhao, F.; Repo, E.; Meng, Y.; Wang, X.; Yin, D.; Sillanpaa, M. An EDTA-beta-cyclodextrin material for the adsorption of rare earth elements and its application in preconcentration of rare earth elements in seawater. J. Coll. Interface Sci. 2016, 465, 215-224. [CrossRef]

15. Abreu, R.D.; Morais, C.A. Study on separation of heavy rare earth elements by solvent extraction with organophosphorus acids and amine reagents. Miner. Eng. 2014, 61, 82-87. [CrossRef]

16. Huang, X.; Dong, J.; Wang, L.; Feng, Z.; Xue, Q.; Meng, X. Selective recovery of rare earth elements from ion-adsorption rare earth element ores by stepwise extraction with HEH(EHP) and HDEHP. Green Chem. 2017, 19, 1345-1352. [CrossRef]

17. Sharaf, M.; Yoshida, W.; Kubota, F.; Goto, M. Selective Extraction of Scandium by a Long Alkyl Chain Carboxylic Acid/Organophosphonic Ester Binary Extractant. Solvent Extr. Ion Exch. 2018, 36, 647-657. [CrossRef]

18. Singh, D.K.; Anitha, M.; Kain, V. Development of solvent extraction process for erbium purification. Sep. Sci. Technol. 2017, 52, 2284-2290. [CrossRef]

19. Chen, J.; Luo, W.; Guo, A.; Luo, T.; Lin, C.; Li, H.; Jing, L. Preparation of a novel carboxylate-rich palygorskite as an adsorbent for Ce3+ from aqueous solution. J. Coll. Interface Sci. 2018, 512, 657-664. [CrossRef]

20. Borai, E.H.; Hamed, M.G.; El-Kamash, A.M.; Siyam, T.; Elsayed, G.O. Template polymerization synthesis of hydrogel and silica composite for sorption of some rare earth elements. J. Coll. Interface Sci. 2015, 456, 228-240. [CrossRef] [PubMed]

21. Florek, J.; Giret, S.; Juère, E.; Larivière, D.; Kleitz, F. Functionalization of mesoporous materials for lanthanide and actinide extraction. Dalton Trans. 2016, 45, 14832-14854. [CrossRef] [PubMed]

22. Gargari, J.E.; Kalal, H.S.; Shakeri, A.; Khanchi, A. Synthesis and characterization of Silica/polyvinyl imidazole/H2PO4-core-shell nanoparticles as recyclable adsorbent for efficient scavenging of Sm(III) and Dy(III) from water. J. Coll. Interface Sci. 2017, 505, 745-755. [CrossRef] [PubMed]

23. Ravi, S.; Lee, Y.-R.; Yu, K.; Ahn, J.-W.; Ahn, W.-S. Benzene triamido-tetraphosphonic acid immobilized on mesoporous silica for adsorption of $\mathrm{Nd} 3+$ ions in aqueous solution. Microporous Mesoporous Mater. 2018, 258, 62-71. [CrossRef]

24. Maranescu, B.; Lupa, L.; Visa, A. Synthesis, characterization and rare earth elements adsorption properties of phosphonate metal organic frameworks. Appl. Surf. Sci. 2019, 481, 83-91. [CrossRef] 
25. Saha, D.; Akkoyunlu, S.D.; Thorpe, R.; Hensley, D.K.; Chen, J. Adsorptive recovery of neodymium and dysprosium in phosphorous functionalized nanoporous carbon. J. Environ. Chem. Eng. 2017, 5, 4684-4692. [CrossRef]

26. Ang, K.L.; Li, D.; Nikoloski, A.N. The effectiveness of ion exchange resins in separating uranium and thorium from rare earth elements in acidic aqueous sulfate media. Part 2. Chelating resins. Miner. Eng. 2018, 123, 8-15. [CrossRef]

27. Fila, D.; Hubicki, Z.; Kołodyńska, D. Recovery of metals from waste nickel-metal hydride batteries using multifunctional Diphonix resin. Adsorption 2019, 25, 367-382. [CrossRef]

28. Galhoum, A.A.; Elshehy, E.A.; Tolan, D.A.; El-Nahas, A.M.; Taketsugu, T.; Nishikiori, K.; Akashi, T.; Morshedy, A.S.; Guibal, E. Synthesis of polyaminophosphonic acid-functionalized poly(glycidyl methacrylate) for the efficient sorption of La(III) and Y(III). Chem. Eng. J. 2019, 375, 121932. [CrossRef]

29. Hérès, X.; Blet, V.; Di Natale, P.; Ouaattou, A.; Mazouz, H.; Dhiba, D.; Cuer, F. Selective Extraction of Rare Earth Elements from Phosphoric Acid by Ion Exchange Resins. Metals 2018, 8, 682. [CrossRef]

30. Park, H.-J.; Tavlarides, L.L. Adsorption of Neodymium(III) from Aqueous Solutions Using a Phosphorus Functionalized Adsorbent. Ind. Eng. Chem. Res. 2010, 49, 12567-12575. [CrossRef]

31. Radhika, S.; Nagaraju, V.; Kumar, B.N.; Kantam, M.L.; Reddy, B.R. Solid-liquid extraction of Gd(III) and separation possibilities of rare earths from phosphoric acid solutions using Tulsion CH-93 and Tulsion CH-90 resins. J. Rare Earths 2012, 30, 1270-1275. [CrossRef]

32. Pinto, J.; Henriques, B.; Soares, J.; Costa, M.; Dias, M.; Fabre, E.; Lopes, C.B.; Vale, C.; Pinheiro-Torres, J.; Pereira, E. A green method based on living macroalgae for the removal of rare-earth elements from contaminated waters. J. Environ. Manag. 2020, 263, 110376. [CrossRef] [PubMed]

33. Ramasamy, D.L.; Porada, S.; Sillanpää, M. Marine algae: A promising resource for the selective recovery of scandium and rare earth elements from aqueous systems. Chem. Eng. J. 2019, 371, 759-768. [CrossRef]

34. Wang, F.; Zhao, J.; Li, W.; Zhou, H.; Yang, X.; Sui, N.; Liu, H. Preparation of Several Alginate Matrix Gel Beads and their Adsorption Properties Towards Rare Earths (III). Waste Biomass Valorization 2013, 4, 665-674. [CrossRef]

35. Song, D.; Park, S.-J.; Kang, H.W.; Bin Park, S.; Han, J.-I. Recovery of Lithium(I), Strontium(II), and Lanthanum(III) Using Ca-Alginate Beads. J. Chem. Eng. Data 2013, 58, 2455-2464. [CrossRef]

36. Wang, F.; Zhao, J.; Pan, F.; Zhou, H.; Yang, X.; Li, W.; Liu, H. Adsorption Properties toward Trivalent Rare Earths by Alginate Beads Doping with Silica. Ind. Eng. Chem. Res. 2013, 52, 3453-3461. [CrossRef]

37. Wang, F.C.; Zhao, J.M.; Wei, X.T.; Huo, F.; Li, W.S.; Hu, Q.Y.; Liu, H.Z. Adsorption of rare earths (III) by calcium alginate-poly glutamic acid hybrid gels. J. Chem. Technol. Biotechnol. 2014, 89, 969-977. [CrossRef]

38. Wu, D.; Zhang, L.; Wang, L.; Zhu, B.; Fan, L. Adsorption of lanthanum by magnetic alginate-chitosan gel beads. J. Chem. Technol. Biotechnol. 2011, 86, 345-352. [CrossRef]

39. Xu, S.; Wang, Z.; Gao, Y.; Zhang, S.; Wu, K. Adsorption of rare earths(III) using an efficient sodium alginate hydrogel cross-linked with poly-gamma-glutamate. PLoS ONE 2015, 10. [CrossRef]

40. Cataldo, S.; Gianguzza, A.; Merli, M.; Muratore, N.; Piazzese, D.; Liveri, M.L.T. Experimental and robust modeling approach for lead(II) uptake by alginate gel beads: Influence of the ionic strength and medium composition. J. Coll. Interface Sci. 2014, 434, 77-88. [CrossRef]

41. Wang, Y.; Feng, Y.; Zhang, X.-F.; Zhang, X.; Jiang, J.; Yao, J. Alginate-based attapulgite foams as efficient and recyclable adsorbents for the removal of heavy metals. J. Coll. Interface Sci. 2018, 514, 190-198. [CrossRef]

42. Guo, Z.; Li, Q.; Li, Z.; Liu, C.; Liu, X.; Liu, Y.; Dong, G.; Lan, T.; Wei, Y. Fabrication of efficient alginate composite beads embedded with $\mathrm{N}$-doped carbon dots and their application for enhanced rare earth elements adsorption from aqueous solutions. J. Coll. Interface Sci. 2020, 562, 224-234. [CrossRef]

43. Wang, S.; Vincent, T.; Faur, C.; Rodriguez-Castellón, E.; Guibal, E. A new method for incorporating polyethyleneimine (PEI) in algal beads: High stability as sorbent for palladium recovery and supported catalyst for nitrophenol hydrogenation. Mater. Chem. Phys. 2019, 221, 144-155. [CrossRef]

44. Wei, Y.; Salih, K.A.M.; Lu, S.; Hamza, M.F.; Fujita, T.; Vincent, T.; Guibal, E. Amidoxime Functionalization of Algal/Polyethyleneimine Beads for the Sorption of Sr(II) from Aqueous Solutions. Molecules 2019, 24, 3893. [CrossRef] [PubMed]

45. Hamza, M.F.; Salih, K.A.M.; Abdel-Rahman, A.A.-H.; Zayed, Y.E.; Wei, Y.; Liang, J.; Guibal, E. Sulfonic-functionalized algal/PEI beads for scandium, cerium and holmium sorption from aqueous solutions (synthetic and industrial samples). Chem. Eng. J. 2021, 403, 126399. [CrossRef]

46. Hamza, M.F.; Wei, Y.; Guibal, E. Quaternization of algal/PEI beads (a new sorbent): Characterization and application to scandium recovery from aqueous solutions. Chem. Eng. J. 2020, 383, 123210. [CrossRef]

47. Lopez-Ramon, M.V.; Stoeckli, F.; Moreno-Castilla, C.; Carrasco-Marin, F. On the characterization of acidic and basic surface sites on carbons by various techniques. Carbon 1999, 37, 1215-1221. [CrossRef]

48. Nayak, A.K.; Pal, A. Development and validation of an adsorption kinetic model at solid-liquid interface using normalized Gudermannian function. J. Mol. Liq. 2019, 276, 67-77. [CrossRef]

49. Shapiro, L. Rapid Analysis of Silicate, Carbonate, and Phosphate Rocks; Report No. 1401; U.S. Geological Survey: Reston, VA, USA, 1975; Volume 76, pp. 3-88.

50. Marczenko, Z. Separation and Spectrophotometric Determination of Elements, 2nd ed.; Ellis Horwood: Chichester, UK, 1986; 678p. 
51. Davies, W.; Gray, W. A rapid and specific titrimetric method for the precise determination of uranium using iron(II) sulphate as reductant. Talanta 1964, 11, 1203-1211. [CrossRef]

52. Nazir, R.; Gaan, S. Recent developments in P(O/S)-N containing flame retardants. J. Appl. Polym. Sci. 2020, 137, 27. [CrossRef]

53. Demadis, K.D.; Paspalaki, M.; Theodorou, J. Controlled Release of Bis(phosphonate) Pharmaceuticals from Cationic Biodegradable Polymeric Matrices. Ind. Eng. Chem. Res. 2011, 50, 5873-5876. [CrossRef]

54. Haug, A. Dissociation of alginic acid. Acta Chem. Scand. 1961, 15, 950-952. [CrossRef]

55. Li, J.-N.; Liu, L.; Fu, Y.; Guo, Q.-X. What are the pKa values of organophosphorus compounds? Tetrahedron 2006, 62, 4453-4462. [CrossRef]

56. Galhoum, A.A.; Eisa, W.H.; El-Sayed, I.E.-T.; Tolba, A.A.; Shalaby, Z.M.; Mohamady, S.I.; Muhammad, S.S.; Hussien, S.S.; Akashi, T.; Guibal, E. A new route for manufacturing poly(aminophosphonic)-functionalized poly(glycidyl methacrylate)-magnetic nanocomposite-Application to uranium sorption from ore leachate. Environ. Pollut. 2020, 264, 114797. [CrossRef]

57. Crank, J. The Mathematics of Diffusion, 2nd ed.; Oxford University Press: Oxford, UK, 1975; 414p.

58. Ho, Y.S.; McKay, G. Pseudo-second order model for sorption processes. Process. Biochem. 1999, 34, 451-465. [CrossRef]

59. Hubbe, M.A.; Azizian, S.; Douven, S. Implications of apparent pseudo-second-order adsorption kinetics onto cellulosic materials: A review. BioResources 2019, 14, 7582-7626. [CrossRef]

60. Persson, I. Hydrated metal ions in aqueous solution: How regular are their structures? Pure Appl. Chem. 2010, 82, 1901-1917. [CrossRef]

61. Marcus, Y. Ion Properties; Marcel Dekker, Inc.: New York, NY, USA, 1997; 259p.

62. Hamza, M.F.; Lu, S.M.; Salih, K.A.M.; Mira, H.; Dhmees, A.S.; Fujita, T.; Wei, Y.Z.; Vincent, T.; Guibal, E. As(V) sorption from aqueous solutions using quaternized algal/polyethyleneimine composite beads. Sci. Total. Environ. 2020, $719,137396$. [CrossRef] [PubMed]

63. Hamza, M.F.; Mubark, A.E.; Wei, Y.; Vincent, T.; Guibal, E. Quaternization of Composite Algal/PEI Beads for Enhanced Uranium Sorption-Application to Ore Acidic Leachate. Gels 2020, 6, 12. [CrossRef] [PubMed]

64. Pearson, R.G. Acids and bases. Science 1966, 151, 172-177. [CrossRef]

65. Iftekhar, S.; Srivastava, V.; Ramasamy, D.L.; Naseer, W.A.; Sillanpää, M. A novel approach for synthesis of exfoliated biopolymericLDH hybrid nanocomposites via in-stiu coprecipitation with gum Arabic: Application towards REEs recovery. Chem. Eng. J. 2018, 347, 398-406. [CrossRef]

66. Rhauderwiek, T.; Zhao, H.; Hirschle, P.; Döblinger, M.; Bueken, B.; Reinsch, H.; De Vos, D.; Wuttke, S.; Kolb, U.; Stock, N. Highly stable and porous porphyrin-based zirconium and hafnium phosphonates-Electron crystallography as an important tool for structure elucidation. Chem. Sci. 2018, 9, 5467-5478. [CrossRef] [PubMed]

67. Sum, J.Y.; Ahmad, A.L.; Ooi, B.S. Selective separation of heavy metal ions using amine-rich polyamide TFC membrane. J. Ind. Eng. Chem. 2019, 76, 277-287. [CrossRef]

68. Surls, J.P.; Choppin, G.R. Equilibrium Sorption of Lanthanides, Americium and Curium on Dowex-50 Resin. J. Am. Chem. Soc. 1957, 79, 855-859. [CrossRef]

69. Philip, L.; Iyengar, L.; Venkobachar, C. Biosorption of U, La, Pr, Nd, Eu and Dy by Pseudomonas aeruginosa. J. Ind. Microbiol. Biotechnol. 2000, 25, 1-7. [CrossRef]

70. Vijayaraghavan, K.; Jegan, J. Entrapment of brown seaweeds (Turbinaria conoides and Sargassum wightii) in polysulfone matrices for the removal of praseodymium ions from aqueous solutions. J. Rare Earths 2015, 33, 1196-1203. [CrossRef]

71. Varshini, J.S.; Das, D.; Das, N. Optimization of parameters for praseodymium(III) biosorption onto biowaste materials using response surface methodology: Equilibrium, kinetic and regeneration studies. Ecol. Eng. 2015, 81, 321-327. [CrossRef]

72. Wang, S.Y.; Hamza, M.F.; Vincent, T.; Faur, C.; Guibal, E. Praseodymium sorption on Laminaria digitata algal beads and foams. J. Coll. Interface Sci. 2017, 504, 780-789. [CrossRef]

73. Saeed, M.M.; Ahmed, M. Effect of Temperature on Kinetics and Adsorption Profile of Endothermic Chemisorption Process: -Tm(III)-PAN Loaded PUF System. Sep. Sci. Technol. 2006, 41, 705-722. [CrossRef]

74. Rangabhashiyam, S.; Vijayaraghavan, K. Biosorption of Tm(III) by free and polysulfone-immobilized Turbinaria conoides biomass J. Ind. Eng. Chem. 2019, 80, 318-324.

75. Iftekhar, S.; Srivastava, V.; Ben Hammouda, S.; Sillanpää, M. Fabrication of novel metal ion imprinted xanthan gum-layered double hydroxide nanocomposite for adsorption of rare earth elements. Carbohydr. Polym. 2018, 194, 274-284. [CrossRef]

76. Daneshvar, E.; Vazirzadeh, A.; Niazi, A.; Kousha, M.; Naushad, M.; Bhatnagar, A. Desorption of Methylene blue dye from brown macroalga: Effects of operating parameters, isotherm study and kinetic modeling. J. Clean. Prod. 2017, 152, 443-453. [CrossRef]

77. Jorjani, E.; Shahbazi, M. The production of rare earth elements group via tributyl phosphate extraction and precipitation stripping using oxalic acid. Arab. J. Chem. 2016, 9, S1532-S1539. [CrossRef]

78. Da Silva, R.G.; Morais, C.A.; Teixeira, L.V.; Oliveira, É.D. Selective Precipitation of High-Quality Rare Earth Oxalates or Carbonates from a Purified Sulfuric Liquor Containing Soluble Impurities. Min. Met. Explor. 2019, 36, 967-977. [CrossRef]

79. Tunsu, C.; Lapp, J.B.; Ekberg, C.; Retegan, T. Selective separation of yttrium and europium using Cyanex 572 for applications in fluorescent lamp waste processing. Hydrometallurgy 2016, 166, 98-106. [CrossRef] 